\title{
Phytogenic Bioactive Compounds Shape Fish Mucosal Immunity
}

\author{
Joana P. Firmino ${ }^{1,2,3}$, Jorge Galindo-Villegas ${ }^{4 *}$, Felipe E. Reyes-López ${ }^{5,6,7}$ \\ and Enric Gisbert ${ }^{1}$
}

${ }^{1}$ Aquaculture Program, Institut de Recerca i Tecnologia Agroalimentàries (IRTA) Centre de Sant Carles de la Ràpita (IRTASCR), Sant Carles de la Ràpita, Spain, 2 PhD Program in Aquaculture, Universitat Autònoma de Barcelona, Bellaterra, Spain, ${ }^{3} R \& D$ Technical Department, TECNOVIT - FARMFAES, S.L., Alforja, Spain, ${ }^{4}$ Faculty of Biosciences and Aquaculture, Nord University, Bodø, Norway, ${ }^{5}$ Department of Cell Biology, Physiology and Immunology, Universitat Autònoma de Barcelona, Bellaterra, Spain, 6 Facultad de Medicina Veterinaria y Agronomía, Universidad de Las Américas, Santiago, Chile, ${ }^{7}$ Consorcio Tecnológico de Sanidad Acuícola, Ictio Biotechnologies S.A., Santiago, Chile

OPEN ACCESS

Edited by:

Javier Santander,

Memorial University of Newfoundland,

Canada

Reviewed by:

Seyed Hossein Hoseinifar, Gorgan University of Agricultural

Sciences and Natural Resources, Iran Débora Torrealba,

Pontificia Universidad Católica de Valparaíso, Chile

*Correspondence:

Jorge Galindo-Villegas jorge.galindo-villegas@nord.no

Specialty section:

This article was submitted to Comparative Immunology, a section of the journal

Frontiers in Immunology

Received: 15 April 2021 Accepted: 31 May 2021

Published: 18 June 2021

Citation:

Firmino JP, Galindo-Villegas J, Reyes-López FE and Gisbert E (2021)

Phytogenic Bioactive Compounds

Shape Fish Mucosal Immunity.

Front. Immunol. 12:695973.

doi: 10.3389/fimmu.2021.695973
Aquaculture growth will unavoidably involve the implementation of innovative and sustainable production strategies, being functional feeds among the most promising ones. A wide spectrum of phytogenics, particularly those containing terpenes and organosulfur compounds, are increasingly studied in aquafeeds, due to their growth promoting, antimicrobial, immunostimulant, antioxidant, anti-inflammatory and sedative properties. This trend relies on the importance of the mucosal barrier in the fish defense. Establishing the phytogenics' mode of action in mucosal tissues is of importance for further use and safe administration. Although the impact of phytogenics upon fish mucosal immunity has been extensively approached, most of the studies fail in addressing the mechanisms underlying their pharmacological effects. Unstandardized testing as an extended practice also questions the reproducibility and safety of such studies, limiting the use of phytogenics at commercial scale. The information presented herein provides insight on the fish mucosal immune responses to phytogenics, suggesting their mode of action, and ultimately encouraging the practice of reliable and reproducible research for novel feed additives for aquafeeds. For proper screening, characterization and optimization of their mode of action, we encourage the evaluation of purified compounds using in vitro systems before moving forward to in vivo trials. The formulation of additives with combinations of compounds previously characterized is recommended to avoid bacterial resistance. To improve the delivery of phytogenics and overcome limitations associated to compounds volatility and susceptibility to degradation, the use of encapsulation is advisable. Besides, newer approaches and dedicated methodologies are needed to elucidate the phytogenics pharmacokinetics and mode of action in depth.

Keywords: immunity, MALT, organosulfurs, terpenes, sustainable aquaculture, teleost, phytogenic additive, TRPV4 


\section{INTRODUCTION}

Sustainable food supply to feed the demand of the projected world population by 2050 is a challenge, in which aquaculture is predicted to be the main source of aquatic dietary proteins. Such growth will unavoidably involve the implementation of innovative aquaculture production strategies, targeting issues related to effective health management and animal welfare (1). In this regard, the development and application of functional feeds represent a sound strategy to improve aquaculture systems, since they provide functional health benefits to animals beyond their nutritional value (2). In this scenario, phytogenics, also known as phytobiotics, are defined as environmentally friendly plant-derived bioactive compounds used as functional feed additives that show positive effects on animal growth and health. Phytogenic often comprise aromatic plants extracts, and essential oils characterized by its richness in biologically active compounds $(3,4)$. In farmed fish, a wide spectrum of phytogenics have been increasingly studied mainly due to their wide repertoire of properties, including growth promotion, and antimicrobial, immunostimulant, antioxidant, anti-inflammatory and sedative activities (5). In particular, phytogenics derived from Lamiaceae family and Allium sp. are among the most commonly studied and administrated plantbased additives $(6,7)$. Nonetheless, the complexity of the mechanisms of action and the pharmacological effects promoted by the diverse bioactive compounds present in such plants, along with their frequently observed synergistic behavior (8), often limits the full understanding of their biological activity (9).

Since outbreaks of fish diseases are one of the main constrains for the progress of the aquaculture sector (10), the inclusion of phytogenics' in aquafeeds is achieving significant attention at a global scale. The impact of phytogenics upon fish systemic immunity has been extensively tested in the past $(5,9)$. However, an increasing trend to evaluate phytogenics' impact upon the mucosal immunity has been gained importance in recent years, which is mainly attributed to the importance of the mucosal barrier in the fish defense against variated threats and, potential colonization and invasion by pathogenic organisms (11). In contrast, most of the studies evaluating the effect of phytogenics in fish systemic immunity are only supported by a selection of repetitive primary analyses (i.e., lysozyme, bacteriolytic and complement activities, immunoglobulins, oxidative stress enzymes, etc.) serving only as proxies, that only provide a snapshot of the effects of the evaluated feed additive on the organism. These approaches do not allow elucidating their mode of action at cellular and molecular levels. This is of special relevance when dealing with functional feed additives with potential pharmacological properties, as their standardized use mainly depends on the proper understanding of their regulatory properties in the immune system.

Phytogenic administration has the potential to regulate the mucosal barrier function by means of several molecular mechanisms, in which the phytogenic bioactive compounds interact with cellular transcription factors and metabolic cascades. Therefore, the modulation of the expression of genes coding for immune relevant molecules alter the mucosal protective characteristics and their immunological status
(12-16). Besides, the immune system influences the regulation and composition of the microbiota and vice versa, an interaction that plays a determinant role in the maintenance of the mucosal integrity and functionality $(17,18)$. Hence, both the improvement of the mucosal barrier characteristics and the modulation of the microbiota are central targets for the development of new phytogenic additives, while understanding their mode of action at cellular and molecular levels is critical for elucidating their benefits to the host.

Given the extended literature available on plant-based functional additives and the significance of the mucosal immunity described above, our review efforts focus exclusively on the physiological and immunological responses achieved by the most studied fish mucosal tissues, intestine, gills and skin, of organisms fed with phytogenics of the Lamiaceae family and Allium sp. In the first part, we present a thorough description on their main bioactive compounds and relevant biological properties. Then, the immunomodulatory properties and the mechanisms they can trigger on the fish mucosal tissues are explored and further potential mechanisms hypothesized. Finally, research gaps and constrains for the development of applicable phytogenic-based additives are discussed. Overall, the information presented herein aims to provide clear insights on the fish mucosal immune response dietary treated with phytogenics, propose viable mechanisms for exploiting them, and ultimately encourage the practice of reliable and reproducible research for the development of novel feed additives to be used as sustainable and safe prophylactic strategies for aquaculture.

\section{FISH MUCOSAL IMMUNITY AT A GLANCE}

The mucosal barrier constitutes the fish first line of defense against the surrounding environment and potential pathogens. Fish mucosal tissues are particularly characterized by a mucosaassociated lymphoid tissue (MALT), harboring diverse myeloid and lymphoid cells that are responsible for the host protection against pathogens and antigens, while tolerating beneficial symbiont colonization to maintain mucosa homeostasis (1921). Six different MALTs have been described so far in teleosts. The gut-associated lymphoid tissue (GALT), the gill-associated lymphoid tissue (GIALT), the skin-associated lymphoid tissue (SALT), the nasopharynx-associated lymphoid tissue (NALT) and, the more recently characterized the buccal, and pharyngeal MALTs (22). Other mucosal immune systems have been hypothesized and are currently under study (23). Despite the existence of others, the GALT, GIALT and SALT are the most studied and well characterized MALTs and therefore selected as target in this review.

Among the extensive cell types with immune capacity coexisting in the fish body, upon sensing the presence of pathogenic or commensal microbe-associated molecular pattern (MAMP) a downstream signaling response mediated through pattern recognition receptors (PRRs) immediately takes place. So far, several piscine PRRs have been identified, being the toll-like receptors (TLR), NOD-like receptors (NLR) and retinoic acid-inducible gene I (RIG-I)-like receptors (RLRs) the best 
characterized $(24,25)$. Epithelial and endothelial cells together with the professional phagocytes, represented by macrophages, granulocytes and dendritic cells, are the first responders against MAMPs formerly sensed by PRRs. Phagocytosis contributes to both pathogen clearance and subsequent antigen presentation to other immune cells by the membrane Major Histocompatibility Complex (MHC) class II peptide complex (26). In most, but not all teleost fish, the peptide-MHC II complex activates naive CD ${ }^{+}$ $\mathrm{T}$ cells expressing antigen-specific $\mathrm{T}$ cell receptors (TCR) in their surface. Recognition of this complex stimulates the dedicated $\mathrm{CD}^{+}$cells activation and differentiation into $\mathrm{T}$ helper cell subsets possessing inflammatory cytokines secreting capacity that further coordinate the adaptive response together with $\mathrm{B}$ cells $(27,28)$. Interestingly, while $\mathrm{CD} 4^{+} \mathrm{T}$ helper lymphocytes are mainly present in the gut lamina propria, the cytotoxic $\mathrm{CD}^{+}$ cells are the dominant intraepithelial resident immunocytes (29-31).

In fact, both $\mathrm{T}$ and $\mathrm{B}$ lymphocytes are abundantly present in fish mucosal tissues (32). Interestingly, the phagocytic and bacterial-killing abilities of $\mathrm{B}$ cells in fish have been fairly introduced in the past (33). However, their antigen presentation mechanisms mediated by MHC II and costimulatory molecules (CD80/CD86 and CD83) to prime naïve $\mathrm{CD}^{+} \mathrm{T}$-cells, produce IgM, IgT, and eventually IgD plasmablasts -a major lymphocyte population in the gut, gill and at some extent the skin-, have just been recently addressed $(34,35)$. The IgT, the teleost specialized mucosal immunoglobulin analogous to mammalian IgA (36), plays a critical role in the clearance of mucosal pathogens and the preservation of microbiota homeostasis through immune exclusion (11). Although extremely important in mucosal defense, not all teleosts present IgT/IgD, which suggests the existence of alternative mucosal immune systems (23).

For instance, the complete $\operatorname{IgM}$ and $\operatorname{IgT}$ sequences in their membrane and soluble forms have been reported and characterized for the first time in a perciform, the gilthead sea bream (Sparus aurata) (37). Interestingly, this study demonstrated that virus and bacteria trigger the mucosal immune response by promoting the activation of IgT in seabream. Although, diets with fish oil replacement by ones from plant origin inhibited the IgT upregulation upon intestinal parasitic challenge, which was related to a worse disease outcome. These results evidenced that mucosal immunoglobulins can be significantly affected by dietary treatments, which highlights the necessity of testing this response case by case.

Although characterized by common cellular components, immune mediators and immune mechanisms, the different composition, organization and functions of MALTs may vary according to each tissue intrinsic and external environmental factors (38), changes that may be associated to the fish species considered. Besides, the microbiota also stands as a relevant component of the mucosal barrier, displaying an antagonistic behavior against invading "hostile" microorganisms and directly participating in the immune responses through the complex host-microbiota crosstalk at the mucosal interface $(17,18)$. Therefore, the selective manipulation of the microbiota by means of nutritional approaches has been previously proposed as a viable alternative to modulate mucosal responses (39).
The mucosal tissues are intrinsically characterized by mucus secreting cells, such as goblet cells (40). Beside playing important roles in intra- and interspecific ecological interactions (41) and being a key component that ensures host-microbiota homeostasis $(42,43)$, the secreted semipermeable mucus represents the first challenge that pathogens have to overcome in order to interact with the host. Its complex composition encompasses a matrix of glycoproteins, the mucins that confer the mucus its structure, and a wide variety of humoral immune factors, such as lysozymes, complement, lectins, proteolytic enzymes, antimicrobial peptides, immunoglobulins, among others (41). Moreover, the mucus is continuously secreted and replaced (44); this continuous secretion aims to prevent pathogen attachment and interaction with the host. Therefore, the presence of a mucus layer is fundamentally involved in the regulation of the mucosal immune system, not only as a protective physical and chemical barrier, but also acting as a vehicle for mucins and humoral immune factors from the inside out. Both goblet cells $(13,15)$ and mucus composition (45) are highly susceptible to be manipulated through dietary strategies, which opens a wide range of possibilities when to design and apply new functional feed additives.

\section{LAMIACEAE FAMILY AND ALLIUM SP. AMONG THE MOST STUDIED AROMATIC PLANTS USED AS PHYTOGENICS IN AQUACULTURE}

In nature, plant secondary metabolites have functional roles independent from plant growth and development; thus, protecting plants from herbivore and pests, or acting as chemoattractants for pollinators (46). These bioactive compounds broadly found in aromatic plants are usually present as mixtures, mainly represented by phenolics and terpenes that are chemically characterized by their aromatic rings (3). Therefore, their benefits as dietary supplements are subject to the variability and complexity of the aromatic compounds mixture, apart from their synergistic effect, their origin, the dietary inclusion level and their pharmokinetics (47).

In particular, phytogenics derived from Lamiaceae family and Allium sp. are among the most widespread administrated plantbased additives in aquaculture (48) and livestock $(6,7)$. These compounds are used for their recognized growth promoting, antimicrobial, immunostimulant, antioxidant, anti-inflammatory and sedative properties. Although they can be found worldwide, some representatives of this group of aromatic plants (i.e., oregano, thyme, basil, menthe, rosemary, sage, marjoram, garlic and onion, among others) are particularly present and traditionally consumed in the Mediterranean area and appreciated in terms of human nutrition and therapy $(49,50)$. The health-promoting properties of these aromatic plants have been extensively reviewed in different aquaculture species $(5,48,51-55)$. However, most of the studies dealing with these functional feed additives were only focused in physiological or biochemical responses, but few of them have 
elucidated the cellular and molecular mechanisms underlying their immunostimulatory capacity.

While the existent information about the inherent effect of these phytogenics upon immune cells is limited under in vitro conditions, numerous in vivo studies have demonstrated an improvement of the fish mucosal immune responses following their administration. A refined complementary search through Web of Science, PubMed and Google Scholar was performed in this review. Until March 2021, 62 publications reporting the nutritional effects of Lamiaceae family and Allium sp., or related bioactive compounds, upon fish mucosal responses were retrieved and their results summarized in Table 1. Importantly, most of them were published in the last year; thus, evidencing the current increasing interest for research on phytogenics targeting mucosal tissues. From the overall bibliographic search results, few publications felt within the objective of the present review and described the cellular or molecular mechanisms underlying fish mucosal immune responses to phytogenics' administration. Studies reporting the application of plant extracts or related compounds as bath treatments or evaluating bactericidal or antiparasitic effects in vitro were excluded from the selection as this review is just focused on the mucosal immune mechanisms. Furthermore, Table 1 omits those results out of the mucosal immunity context, including systemic immunity-related results, non-immune digestive parameters or other complementary analysis performed within each study. Although such variables are extensively used as key performance indicators in such studies, their relevance in terms of supporting and/or establishing the mode of action of phytogenics is questionable and out of the scope for this review. Finally, blends with other components besides the selected group of plants -or associated bioactive compounds such as terpenes or organosulfurs- were excluded as well.

\section{Effect of Dietary Terpene Phenolic Compounds Upon Fish Mucosal Immunity}

Phenolics and terpenes are a group of volatile plant-derived bioactive compounds with medicinal and biotechnological value that constitute the dominant fraction of the essential oils derived from aromatic plants (3). The monoterpenes carvacrol and its isomer thymol are the most studied phenolic compounds, representing the major components of the essential oils from several aromatic plants of the Lamiaceae family like the oregano (Origanum vulgare) and thyme (Thymus vulgaris) $(109,110)$. These compounds are particularly studied and recognized for their bactericidal activity, since their lipophilic character act as bacterial membrane permeabilizers with cytotoxic effects upon bacterial structure and function, leading to membrane expansion, fluidity and permeability, disturbance of the membrane-embedded proteins, respiration inhibition and alteration of ion transport. In addition, carvacrol and thymol were demonstrated to act as quorum sensing (QS) inhibitors, reducing bacterial biofilm formation. Carvacrol in particular, is able to inhibit bacteria motility, collapsing the proton-motive force, depleting the ATP pools and preventing the synthesis of flagellin (111). This bactericidal property highlights the ability of these compounds to potentially modulate mucosal tissues associated microbiota.
Together with their well-studied bactericidal potential, these phenolic compounds are described to potentially improve the integrity of the mucosal tissues due to their observed antioxidant, anti-inflammatory and consequent immunomodulatory properties in the gastrointestinal mucosa of several animal models (112). The reported strong antioxidant activity of carvacrol and thymol rely on their ability to scavenge free radicals, inhibiting reactive oxygen species (ROS) and other oxygen radicals generated in cells and tissues (113). By contrast, high concentrations may display antagonistic prooxidant effects (113). This dose-dependent antagonistic activity evidences the importance of correctly define their administration doses in order to obtain the desired results with regard to their immunomodulatory properties.

Regarding their anti-inflammatory potential, carvacrol and thymol appear to interfere with the NF- $k \mathrm{~B}$ and MAPK pathways, modulating the expression of pro-inflammatory and antiinflammatory cytokines $(114,115)$. It is commonly speculated that the anti-inflammatory properties of plant-derived bioactive compounds, such as carvacrol and thymol, may be attributed to their capacity to inhibit TLR-mediated NF- $k$ B signaling pathways $(116,117)$. Furthermore, evidence that both carvacrol and thymol play a role in the chemosensory system through the activation of transient receptor potential (TRP) cation channels exist $(118,119)$. In higher vertebrates, TRP channels are widely expressed in several cellular types that includes most of the mucosal components. Through the maintenance of the intracellular calcium homeostasis, these channels are known to regulate several cell functions, such as stimuli perception, inflammatory molecules production and secretion, migration and even phagocytosis (120122). Carvacrol and thymol are known to activate both the receptor TRPA1 (119) and the receptor TRPV3 in mucosal tissues, elevating cytosolic $\mathrm{Ca}^{2+}$ concentration in epithelial cells $(118,123)$. In fish, together with TLRs, the activation of TRP channels has been demonstrated to modulate the inflammatory processes through the activation of the TRP/Ca ${ }^{2+} / \mathrm{TAK} 1 / \mathrm{NF}-k \mathrm{~B}$ signaling pathway (124). This suggests that a TRP channel mediated cellular activation may underlie the immunomodulatory properties of these bioactive compounds.

The health promoting effects of oregano, thyme and their derivates in fish have been recently reviewed $(55,125)$. Concerning their impact upon fish mucosal immunity, several nutritional studies have described beneficial effects of phytogenics derived from oregano, thyme and other plants of the Lamiaceae family upon the mucosal tissues in several fish species (Table 1). Most of them have reported an increase in skin mucus immune markers and/or skin mucus bactericidal activity (56-58, 65, 71, 73-79). The repeatedly evaluated markers were lysozyme, alkaline phosphatase, complement and protease activities, total immunoglobulin and protein content in fish skin mucus, as well as its in vitro bactericidal potential against bacterial pathogens. Several of these studies also described an improvement in key performance indicators, such growth, feed efficiency and survival against pathogenic bacterial challenges $(56,58,65,71,73-79)$. Besides the assessment of key performance indicators and general immune markers in skin 
TABLE 1 | Extended summary of the current available literature on nutritional effects of Lamiaceae family and Allium sp. derived phytogenics upon fish mucosal immune response.

\begin{tabular}{|c|c|c|c|c|c|c|c|c|c|}
\hline $\begin{array}{l}\text { Phytogenic } \\
\text { plant origin }\end{array}$ & $\begin{array}{l}\text { Supplemented } \\
\text { form }\end{array}$ & $\begin{array}{l}\text { Inclusion } \\
\text { dosage(s) } \\
\text { tested }\end{array}$ & $\begin{array}{c}\text { Period of } \\
\text { administration }\end{array}$ & $\begin{array}{l}\text { Main bioactive } \\
\text { components ( } \leq 3)\end{array}$ & Fish species & Performance & Mucosal parameters evaluation & Key benefits summary & Reference \\
\hline \multicolumn{10}{|c|}{ Lamiaceae family } \\
\hline $\begin{array}{l}\text { Oregano } \\
\text { (Origanum } \\
\text { vulgare) }\end{array}$ & Powder & $\begin{array}{l}0.5 \% \\
1.0 \% \text { and } \\
2.0 \%\end{array}$ & 8 weeks & $\mathrm{N} / \mathrm{l}$ & $\begin{array}{l}\text { Zebrafish (Danio } \\
\text { rerio) }\end{array}$ & $\begin{array}{l}\uparrow \text { Final weight } \\
\uparrow \text { Weight gain } \\
\downarrow \text { FCR } \\
\uparrow \text { SGR } \\
\uparrow \text { Survival } \\
\text { against } A \text {. } \\
\text { hydrophila }\end{array}$ & $\begin{array}{l}\uparrow \text { Skin mucus lysozyme activity } \\
\uparrow \text { Skin mucus alkaline phosphatase } \\
\text { activity } \\
\uparrow \text { Skin mucus total lg } \\
\uparrow \text { Skin mucus protease activity } \\
\uparrow \text { Skin mucus total protein }\end{array}$ & $\begin{array}{l}\text { Beneficially affects the skin mucus } \\
\text { immune parameters, growth } \\
\text { performance and survival against } \\
\text { pathogenic bacterial challenge }\end{array}$ & $\begin{array}{l}\text { Rashidian, Boldaji } \\
\text { (56) }\end{array}$ \\
\hline $\begin{array}{l}\text { Oregano } \\
\text { (Origanum } \\
\text { vulgare) }\end{array}$ & Powder & $\begin{array}{l}0.5 \% \text { and } \\
1.0 \%\end{array}$ & $\begin{array}{l}15 \text { and } \\
30 \text { days }\end{array}$ & $\mathrm{N} / \mathrm{I}$ & $\begin{array}{l}\text { Gilthead seabream } \\
\text { (Sparus aurata) }\end{array}$ & No effect & $\begin{array}{l}\uparrow \text { Skin mucus IgM } \\
\uparrow \text { Skin mucus bactericidal activity } \\
\text { against } P \text {. damselae }\end{array}$ & $\begin{array}{l}\text { Oregano improves humoral immunity } \\
\text { and increases the antibacterial activity } \\
\text { of skin mucus }\end{array}$ & $\begin{array}{l}\text { Beltrán, Gonzalez } \\
\text { Silvera (57) }\end{array}$ \\
\hline $\begin{array}{l}\text { Oregano } \\
\text { (Origanum } \\
\text { vulgare) }\end{array}$ & Ethanolic extract & $\begin{array}{l}0.2 \% \text { and } \\
0.5 \%\end{array}$ & $\begin{array}{l}60 \text { days }+7 \\
\text { days } A \text {. } \\
\text { hydrophila } \\
\text { challenge }\end{array}$ & $\mathrm{N} / \mathrm{l}$ & $\begin{array}{l}\text { Nile tilapia } \\
\text { (Oreochromis } \\
\text { niloticus) }\end{array}$ & $\begin{array}{l}\uparrow \text { Final weight } \\
\uparrow \text { Weight gain } \\
\downarrow \text { FCR } \\
\uparrow \text { SGR } \\
\uparrow \text { Survival rate } \\
\uparrow \text { Survival } \\
\text { against } A \text {. } \\
\text { hydrophila }\end{array}$ & $\uparrow$ Skin mucus total Ig & $\begin{array}{l}\text { Can effectively improve the fish } \\
\text { growth, health, and immune status }\end{array}$ & $\begin{array}{l}\text { Mohammadi, } \\
\text { Rafiee (58) }\end{array}$ \\
\hline $\begin{array}{l}\text { Oregano } \\
\text { (Origanum } \\
\text { vulgare) }\end{array}$ & Powder & $\begin{array}{l}5.0,10.0,15.0 \\
\text { and } 20.0 \mathrm{~g} \mathrm{~kg}^{-}\end{array}$ & 8 weeks & $\begin{array}{l}\text { Carvacrol and thymol } \\
\text { (Commercial product) }\end{array}$ & $\begin{array}{l}\text { Common carp } \\
\text { (Cyprinus carpio) }\end{array}$ & $\begin{array}{l}\uparrow \text { Final weight } \\
\uparrow \text { Weight gain } \\
\uparrow \text { SGR }\end{array}$ & $\begin{array}{l}\uparrow \text { Intestine villus height } \\
\uparrow \text { Intestine villus width } \\
\uparrow \text { Intestine crypt depth }\end{array}$ & $\begin{array}{l}\text { Dose-dependent enhancement of } \\
\text { intestinal morphometry, which } \\
\text { subsequently lead to improvement of } \\
\text { nutrients absorption }\end{array}$ & $\begin{array}{l}\text { Abdel-Latif, Abdel- } \\
\text { Tawwab (59) }\end{array}$ \\
\hline $\begin{array}{l}\text { Oregano } \\
\text { (Origanum } \\
\text { vulgare) }\end{array}$ & Essential oils & $\begin{array}{l}0.75,1.5,2.25 \\
\text { and } 3.0 \mathrm{~g} \mathrm{~kg}^{-1}\end{array}$ & 64 days & $\begin{array}{l}\text { Carvacrol, thymol and } \\
\text { p-cymene }\end{array}$ & $\begin{array}{l}\text { Nile tilapia } \\
\text { (Oreochromis } \\
\text { niloticus) }\end{array}$ & No effect & $\uparrow$ Intestine villus height & Increases intestinal villus size & Heluy, Ramos (60) \\
\hline $\begin{array}{l}\text { Oregano } \\
\text { (Origanum } \\
\text { vulgare) }\end{array}$ & Essential oils & $\begin{array}{l}0.5,1.5 \text { and } \\
4.5 \mathrm{~g} \mathrm{~kg}^{-1}\end{array}$ & $\begin{array}{l}8 \text { weeks }+7 \\
\text { days } A . \\
\text { hydrophila } \\
\text { challenge }\end{array}$ & $\mathrm{N} / \mathrm{l}$ & $\begin{array}{l}\text { Koi carp (Cyprinus } \\
\text { carpio) }\end{array}$ & $\begin{array}{l}\uparrow \text { Survival } \\
\text { against } A \text {. } \\
\text { hydrophila }\end{array}$ & $\begin{array}{l}\downarrow \text { TNF-a and TGF-b gene expression } \\
\text { in intestine } \\
\uparrow \text { Actinobacteria phylum, and } \\
\text { Propionibacterium, Brevinema and } \\
\text { Corynebacterium genera } \\
\downarrow \text { Bacteroidetes phylum and Vibrio } \\
\text { genus } \\
\text { No effect on bacterial alpha diversity }\end{array}$ & $\begin{array}{l}\text { Presents immunomodulatory effects } \\
\text { and enhances disease resistance. } \\
\text { Also beneficially alters the gut bacterial } \\
\text { community composition of fish }\end{array}$ & Zhang, Wang (61) \\
\hline $\begin{array}{l}\text { Oregano } \\
\text { (Origanum } \\
\text { vulgare) }\end{array}$ & Powder & $\begin{array}{l}0.5 \% \text { and } \\
1.0 \%\end{array}$ & $\begin{array}{l}30 \text { days }+ \\
\text { cypermethrin } \\
\text { exposure }\end{array}$ & $\begin{array}{l}\text { Carvacrol and thymol } \\
\text { (Commercial product) }\end{array}$ & $\begin{array}{l}\text { Common carp } \\
\text { (Cyprinus carpio) }\end{array}$ & $\mathrm{N} / \mathrm{I}$ & $\begin{array}{l}\downarrow \text { Gill histopathologic lesions } \\
\downarrow \text { Gill proliferating cell nuclear antigen } \\
\text { (PCNA) and caspase- } 3 \text { immune } \\
\text { positive cells }\end{array}$ & $\begin{array}{l}\text { Protective roles against the adverse } \\
\text { effects of cypermethrin, enhancing } \\
\text { recovery from the exposure }\end{array}$ & Khafaga, Naiel (62) \\
\hline $\begin{array}{l}\text { Oregano } \\
\text { (Origanum } \\
\text { vulgare) }\end{array}$ & Essential oils & $\begin{array}{l}0.01 \%, 0.02 \% \\
0.05 \% \text { and } \\
0.10 \%\end{array}$ & $\begin{array}{l}24 \text { days }+28 \\
\text { days } I . \text { salmonis } \\
\text { and } T \text {. truttae } \\
\text { challenge } \\
\text { (Total } 52 \text { days) }\end{array}$ & $\begin{array}{l}\text { Carvacrol, p-cymene and } \gamma \text { - } \\
\text { terpinene }\end{array}$ & $\begin{array}{l}\text { Chum salmon } \\
\text { (Oncorhynchus keta) }\end{array}$ & $\begin{array}{l}\uparrow \text { feed efficiency } \\
\downarrow 1 \text { salmonis } \\
\text { infection } \\
\downarrow T \text {. truttae } \\
\text { infection } \\
\downarrow \text { cumulative } \\
\text { mortality }\end{array}$ & $\begin{array}{l}\text { Carvacrol content detected in the skin } \\
\text { of fish fed the oregano supplemented } \\
\text { diet }\end{array}$ & $\begin{array}{l}\text { Preventive effects against I. salmonis } \\
\text { and } T \text {. truttae and suggests the } \\
\text { possibility that its anti-parasitic action } \\
\text { is attributable to the bioactive } \\
\text { component emergence through the } \\
\text { skin }\end{array}$ & $\begin{array}{l}\text { Mizuno, Urawa } \\
\text { (63) }\end{array}$ \\
\hline $\begin{array}{l}\text { Oregano } \\
\text { (Origanum } \\
\text { vulgare) }\end{array}$ & Essential oils & $\begin{array}{l}0.5,1.0,1.5 \\
2.0 \\
\text { and } 2.5 \mathrm{~g} \mathrm{~kg}^{-1}\end{array}$ & 90 days & $\begin{array}{l}\mathrm{N} / \mathrm{I} \\
\text { (Commercial product) }\end{array}$ & $\begin{array}{l}\text { Yellow } \\
\text { tail tetra (Astyanax } \\
\text { altiparanae) }\end{array}$ & $\mathrm{N} / \mathrm{l}$ & $\begin{array}{l}\uparrow \text { Intestine villus length } \\
\uparrow \text { Intestine villus width } \\
\uparrow \text { Intestine absorption area } \\
\uparrow \downarrow \text { Intestine goblet cells number }\end{array}$ & $\begin{array}{l}\text { Promotes increased absorption } \\
\text { surface area and modulates the } \\
\text { number of goblet cells involved in } \\
\text { protecting the intestinal mucosa }\end{array}$ & $\begin{array}{l}\text { Ferreira, Caldas } \\
(64)\end{array}$ \\
\hline $\begin{array}{l}\text { Marjoram } \\
\text { (Origanum } \\
\text { majorana) }\end{array}$ & Ethanolic extract & $\begin{array}{l}0.1,0.2 \text { and } \\
0.4 \mathrm{~g} \mathrm{~kg}^{-1}\end{array}$ & $\begin{array}{l}60 \text { days }+10 \\
\text { days } A \text {. } \\
\text { hydrophila } \\
\text { challenge }\end{array}$ & $\mathrm{N} / \mathrm{l}$ & $\begin{array}{l}\text { Common carp } \\
\text { (Cyprinus carpio) }\end{array}$ & $\begin{array}{l}\uparrow \text { Final weight } \\
\uparrow \text { Weight gain } \\
\downarrow \text { FCR } \\
\uparrow \text { SGR } \\
\uparrow \text { Survival } \\
\text { against } A \text {. } \\
\text { hydrophila }\end{array}$ & $\begin{array}{l}\uparrow \text { Skin mucus alkaline phosphatase } \\
\uparrow \text { Skin mucus total lg } \\
\uparrow \text { Skin mucus lysozyme activity } \\
\uparrow \text { Skin mucus alternative complement } \\
\text { (ACH50) activity }\end{array}$ & $\begin{array}{l}\text { Increase fish skin mucosal immunity } \\
\text { and performance }\end{array}$ & $\begin{array}{l}\text { Yousefi, } \\
\text { Ghafarifarsani (65) }\end{array}$ \\
\hline $\begin{array}{l}\text { Thyme } \\
\text { (Thymus } \\
\text { vulgaris) }\end{array}$ & Essential oils & 500 ppm & $\begin{array}{l}30 \text { days }+ \\
\text { thiamethoxam } \\
\text { exposure }\end{array}$ & $\begin{array}{l}\text { Thymol, p-cymene and } \gamma \text { - } \\
\text { terpinene }\end{array}$ & $\begin{array}{l}\text { African catfish } \\
\text { (Clarias garipenus) }\end{array}$ & $\mathrm{N} / \mathrm{l}$ & $\downarrow$ Gill histopathologic lesions & $\begin{array}{l}\text { Mitigate the thiamethoxam induced } \\
\text { toxicity }\end{array}$ & $\begin{array}{l}\text { El Euony, Elblehi } \\
\text { (66) }\end{array}$ \\
\hline $\begin{array}{l}\text { Thyme } \\
\text { (Thymus } \\
\text { vulgaris) }\end{array}$ & Aqueous extract & $\begin{array}{l}5.0,10.0 \text { and } \\
20.0 \mathrm{~g} \mathrm{~kg}^{-1}\end{array}$ & $\begin{array}{l}2 \text { weeks }+ \\
\text { oxytetracycline }\end{array}$ & $\mathrm{N} / \mathrm{l}$ & $\begin{array}{l}\text { Rainbow trout } \\
\text { (Oncorhynchus } \\
\text { mykiss) }\end{array}$ & No effect & $\begin{array}{l}\text { † Intestine antioxidant enzymes (SOD, } \\
\text { CAT, GPx and GST) activity } \\
\downarrow \text { Intestine levels of the oxidative } \\
\text { stress marker malondialdehyde }\end{array}$ & $\begin{array}{l}\text { Mitigate adverse effects of } \\
\text { oxytetracycline and improve the fish } \\
\text { immune responses }\end{array}$ & $\begin{array}{l}\text { Hoseini and } \\
\text { Yousefi (67) }\end{array}$ \\
\hline
\end{tabular}


TABLE 1 | Continued

\begin{tabular}{|c|c|c|c|c|c|c|c|c|c|}
\hline $\begin{array}{l}\text { Phytogenic } \\
\text { plant origin }\end{array}$ & $\begin{array}{l}\text { Supplemented } \\
\text { form }\end{array}$ & $\begin{array}{l}\text { Inclusion } \\
\text { dosage(s) } \\
\text { tested }\end{array}$ & $\begin{array}{c}\begin{array}{c}\text { Period of } \\
\text { administration }\end{array}\end{array}$ & $\begin{array}{l}\text { Main bioactive } \\
\text { components ( } \leq 3)\end{array}$ & Fish species & Performance & Mucosal parameters evaluation & Key benefits summary & Reference \\
\hline $\begin{array}{l}\text { Thyme } \\
\text { (Thymus } \\
\text { vulgaris) }\end{array}$ & Essential oils & $\begin{array}{l}0.1 \%, 0.5 \% \\
\quad \text { and } 1 \%\end{array}$ & 15 days & Thymol, o-cymene and carvacrol & $\begin{array}{l}\text { Nile tilapia } \\
\text { (Oreochromis } \\
\text { niloticus) }\end{array}$ & $\mathrm{N} / \mathrm{l}$ & $\begin{array}{l}\text { No effect upon the population of } \\
\text { beneficial Bacillus bacteria in the gut }\end{array}$ & $\begin{array}{l}\text { Stimulated the cellular components of } \\
\text { the non-specific immune response } \\
\text { without deleterious effects on the } \\
\text { general health of the fish or the } \\
\text { intestinal tract }\end{array}$ & $\begin{array}{l}\text { Valladão, Gallani } \\
\text { (68) }\end{array}$ \\
\hline $\begin{array}{l}\text { Thyme } \\
\text { (Thymus } \\
\text { vulgaris) }\end{array}$ & Essential oils & $\begin{array}{c}0.005,0.010 \\
\text { and } 0.02 \\
\mathrm{~kg}^{-1}\end{array}$ & 5 weeks & $\begin{array}{l}\text { Thymol, p-cymene and } \\
\text { linalool }\end{array}$ & $\begin{array}{l}\text { Rainbow trout } \\
\text { (Oncorhynchus } \\
\text { mykiss) }\end{array}$ & No effect & $\begin{array}{l}\text { No effect upon the allochthonous } \\
\text { microbiota profile }\end{array}$ & $\begin{array}{l}\text { No toxic effects do not significantly } \\
\text { alter the intestinal contents bacterial } \\
\text { populations }\end{array}$ & $\begin{array}{l}\text { Navarrete, Toledo } \\
\text { (69) }\end{array}$ \\
\hline $\begin{array}{l}\text { Spanish } \\
\text { thyme } \\
\text { (Thymus } \\
\text { zygis subsp. } \\
\text { gracilis) }\end{array}$ & Essential oils & $\begin{array}{l}0.001,0.002 \\
0.003 \text { and } \\
0.004 \mathrm{~g} \mathrm{~kg}^{-1}\end{array}$ & 12 weeks & Thymol, p-cymene and carvacrol & $\begin{array}{l}\text { Gilthead seabream } \\
\text { (Sparus aurata) }\end{array}$ & No effect & $\begin{array}{l}\uparrow \text { Anterior intestine lymphocyte } \\
\text { aggregates in the lamina propria at } \\
\text { low dose } \\
\downarrow \text { Anterior intestine lymphocyte } \\
\text { aggregates in the lamina propria at } \\
\text { high doses }\end{array}$ & $\begin{array}{l}\text { Dose-dependent immuno-modulatory } \\
\text { effect upon the intestine }\end{array}$ & $\begin{array}{l}\text { Hernandez, Garcia } \\
\text { (70) }\end{array}$ \\
\hline $\begin{array}{l}\text { Lemon balm } \\
\text { (Melissa } \\
\text { officinalis) }\end{array}$ & Ethanolic extract & $\begin{array}{l}0.2 \% \text { and } \\
0.5 \%\end{array}$ & $\begin{array}{l}60 \text { days }+7 \\
\text { days } A \text {. } \\
\text { hydrophila } \\
\text { challenge }\end{array}$ & $\mathrm{N} / \mathrm{I}$ & $\begin{array}{l}\text { Nile tilapia } \\
\text { (Oreochromis } \\
\text { niloticus) }\end{array}$ & $\begin{array}{l}\uparrow \text { Final weight } \\
\uparrow \text { Weight gain } \\
\downarrow \text { FCR } \\
\uparrow \text { SGR } \\
\uparrow \text { Survival rate } \\
\uparrow \text { Survival } \\
\text { against } A \text {. } \\
\text { hydrophila }\end{array}$ & $\begin{array}{l}\uparrow \text { Skin mucus total Ig } \\
\uparrow \text { Skin mucus lysozyme activity } \\
\uparrow \text { Skin mucus protease activity } \\
\uparrow \text { Skin mucus alternative complement } \\
\text { (ACH50) activity }\end{array}$ & $\begin{array}{l}\text { Can effectively improve the fish } \\
\text { growth, health, and immune status }\end{array}$ & $\begin{array}{l}\text { Mohammadi, } \\
\text { Rafiee (58) }\end{array}$ \\
\hline $\begin{array}{l}\text { Peppermint } \\
\text { (Mentha } \\
\text { piperita) }\end{array}$ & Powder & $\begin{array}{l}2.0,3.0, \text { and } \\
4.0 \mathrm{~g} \mathrm{~kg}^{-1}\end{array}$ & 8 weeks & $\mathrm{N} / \mathrm{I}$ & $\begin{array}{l}\text { Caspian roach } \\
\text { (Rutilus caspicus) }\end{array}$ & $\begin{array}{l}\uparrow \text { Final weight } \\
\uparrow \text { Weight gain } \\
\downarrow \text { FCR } \\
\uparrow \text { SGR } \\
\downarrow \text { Daily intake } \\
\text { rate }\end{array}$ & $\begin{array}{l}\uparrow \text { Secretion of skin mucosal protein } \\
\text { pattern bands; higher lysozyme band } \\
\text { intensity in particular } \\
\uparrow \text { Skin mucus lysozyme activity } \\
\uparrow \text { Skin mucus alkaline phosphatase } \\
\text { activity } \\
\uparrow \text { Skin mucus soluble protein }\end{array}$ & $\begin{array}{l}\text { Act as a growth promoter and } \\
\text { immunostimulant }\end{array}$ & $\begin{array}{l}\text { Paknejad, Hosseini } \\
\text { Shekarabi (71) }\end{array}$ \\
\hline $\begin{array}{l}\text { Peppermint } \\
\text { (Mentha } \\
\text { piperita) }\end{array}$ & Essential oils & $\begin{array}{c}0.1 \mathrm{and}^{-0.25 \mathrm{~g}} \\
\mathrm{~kg}^{-1}\end{array}$ & $\begin{array}{l}7,14,30 \text { and } \\
60 \text { days }\end{array}$ & $\begin{array}{l}\text { Menthol, mentone and 1,8- } \\
\text { cineole }\end{array}$ & $\begin{array}{l}\text { Nile tilapia } \\
\text { (Oreochromis } \\
\text { niloticus) }\end{array}$ & $\mathrm{N} / \mathrm{I}$ & $\uparrow$ Intestine intraepithelial lymphocytes & $\begin{array}{l}\text { Show benefits in terms of intestinal } \\
\text { health and on immune parameters }\end{array}$ & $\begin{array}{l}\text { Valladão, Gallani } \\
\text { (72) }\end{array}$ \\
\hline $\begin{array}{l}\text { Peppermint } \\
\text { (Mentha } \\
\text { piperita) }\end{array}$ & Ethanolic extract & $\begin{array}{l}1.0 \%, 2.0 \% \\
\text { and } 3.0 \%\end{array}$ & 8 weeks & $\mathrm{N} / \mathrm{I}$ & $\begin{array}{l}\text { Rainbow trout } \\
\text { (Onchorhynchus } \\
\text { mykiss) }\end{array}$ & $\begin{array}{l}\uparrow \text { Survival } \\
\text { against } A \text {. } \\
\text { hydrophila }\end{array}$ & $\begin{array}{l}\uparrow \text { Skin mucus antibacterial activity } \\
\text { against } S \text {. iniae, } Y \text {. ruckeri, } A \text {. } \\
\text { hydrophila and L. garviea }\end{array}$ & $\begin{array}{l}\text { Triggers the immune system of } \\
\text { rainbow trout against } Y \text {. ruckeri }\end{array}$ & $\begin{array}{l}\text { Adel, Pourgholam } \\
\text { (73) }\end{array}$ \\
\hline $\begin{array}{l}\text { Peppermint } \\
\text { (Mentha } \\
\text { piperita) }\end{array}$ & Ethanolic extract & $\begin{array}{l}1.0 \%, 2.0 \% \\
\text { and } 3.0 \%\end{array}$ & 56 days & $\mathrm{N} / \mathrm{l}$ & $\begin{array}{l}\text { Caspian kutum } \\
\text { roach (Rutilus frisii } \\
\text { kutum) }\end{array}$ & $\begin{array}{l}\uparrow \text { Weight gain } \\
\downarrow \text { FCR } \\
\uparrow \text { SGR }\end{array}$ & $\begin{array}{l}\uparrow \text { Skin mucus antibacterial activity } \\
\text { against S. iniae, } Y \text {. ruckeri, L. } \\
\text { monocytogenes and E. coli } \\
\uparrow \text { Skin mucus protein level } \\
\uparrow \text { Skin mucus alkaline phosphatase } \\
\text { activity }\end{array}$ & $\begin{array}{l}\text { Increases the mucosal immune } \\
\text { parameters and performance of fry in } \\
\text { a dose dependent manner }\end{array}$ & Adel, Amiri (74) \\
\hline $\begin{array}{l}\text { Peppermint } \\
\text { (Mentha } \\
\text { piperita) }\end{array}$ & Ethanolic extract & $\begin{array}{l}1.0 \%, 2.0 \% \\
\text { and } 3.0 \%\end{array}$ & 8 weeks & $\mathrm{N} / \mathrm{I}$ & $\begin{array}{l}\text { Caspian brown trout } \\
\text { (Salmo trutta } \\
\text { caspius) }\end{array}$ & $\begin{array}{l}\uparrow \text { Weight gain } \\
\downarrow \text { FCR } \\
\uparrow \text { SGR }\end{array}$ & $\begin{array}{l}\text { } \text { Skin mucus protein level } \\
\uparrow \text { Skin mucus lysozyme activity } \\
\uparrow \text { Skin mucus alkaline phosphatase } \\
\text { activity }\end{array}$ & $\begin{array}{l}\text { Promote growth performance and } \\
\text { have immunostimulant properties }\end{array}$ & Adel, Safari (75) \\
\hline $\begin{array}{l}\text { Horsemint } \\
\text { (Mentha } \\
\text { longifolia) }\end{array}$ & Ethanolic extract & $\begin{array}{l}2.0 \%, 4.0 \% \\
\text { and } 6.0 \%\end{array}$ & $\begin{array}{l}8 \text { weeks }+Y \text {. } \\
\text { ruckeri challenge }\end{array}$ & $\mathrm{N} / \mathrm{l}$ & $\begin{array}{l}\text { Caspian kutum } \\
\text { roach (Rutilus frisii } \\
\text { kutum) }\end{array}$ & $\begin{array}{l}\uparrow \text { Weight gain } \\
\downarrow \text { FCR } \\
\uparrow \text { SGR } \\
\uparrow \text { Survival rate }\end{array}$ & $\begin{array}{l}\uparrow \text { Skin mucus protein level } \\
\uparrow \text { Skin mucus lysozyme activity } \\
\uparrow \text { Skin mucus alkaline phosphatase } \\
\text { activity } \\
\uparrow \text { Skin mucus protease activity } \\
\uparrow \text { Skin mucus esterase activity } \\
\uparrow \text { Skin mucus antibacterial activity } \\
\text { against S. iniae, Y. ruckeri, A. } \\
\text { hydrophila and L. garvieae }\end{array}$ & $\begin{array}{l}\text { Improve growth performance and } \\
\text { boost fish immune response in a } \\
\text { dose-related manner }\end{array}$ & $\begin{array}{l}\text { Gholamhosseini, } \\
\text { Adel (76) }\end{array}$ \\
\hline $\begin{array}{l}\text { Horsemint } \\
\text { (Mentha } \\
\text { longifolia) }\end{array}$ & $\begin{array}{l}\text { Hydroalcoholic } \\
\text { extract }\end{array}$ & $\begin{array}{l}0.1 \%, 0.2 \% \\
\text { and } 0.3 \%\end{array}$ & $\begin{array}{l}4 \text { weeks }+10 \\
\text { days } Y \text {. ruckeri } \\
\text { challenge }\end{array}$ & $\mathrm{N} / \mathrm{I}$ & $\begin{array}{l}\text { Rainbow trout } \\
\text { (Onchorhynchus } \\
\text { mykiss) }\end{array}$ & $\begin{array}{l}\uparrow \text { Survival } \\
\text { against } Y . \\
\text { ruckeri }\end{array}$ & $\begin{array}{l}1 \text { Secretion of skin mucosal protein } \\
\text { pattern bands; higher lysozyme band } \\
\text { intensity in particular }\end{array}$ & $\begin{array}{l}\text { Dose-related positive effect on } \\
\text { immunogenicity and increased } \\
\text { resistance to bacterial disease }\end{array}$ & $\begin{array}{l}\text { Heydari, } \\
\text { Firouzbakhsh (77) }\end{array}$ \\
\hline $\begin{array}{l}\text { Thumbai } \\
\text { (Leucas } \\
\text { aspera) }\end{array}$ & Powder & $\begin{array}{l}1.0,2.0,4.0 \\
\text { and } \\
8.0 \mathrm{~g} \mathrm{~kg}^{-1}\end{array}$ & $\begin{array}{l}45 \text { days }+15 \\
\text { days } S \text {. } \\
\text { agalactiae } \\
\text { challenge }\end{array}$ & $\mathrm{N} / \mathrm{l}$ & $\begin{array}{l}\text { Nile tilapia } \\
\text { (Oreochromis } \\
\text { niloticus) }\end{array}$ & $\begin{array}{l}\uparrow \text { Weight gain } \\
\downarrow \text { FCR } \\
\uparrow \text { SGR } \\
\uparrow \text { Survival }\end{array}$ & $\begin{array}{l}\uparrow \text { Skin mucus lysozyme activity } \\
\uparrow \text { Skin mucus peroxidase activity }\end{array}$ & $\begin{array}{l}\text { Increase skin mucosal immune } \\
\text { parameters, performance and survival } \\
\text { against bacterial infection }\end{array}$ & $\begin{array}{l}\text { Kurian, Van Doan } \\
\text { (78) }\end{array}$ \\
\hline
\end{tabular}




\begin{tabular}{|c|c|c|c|c|c|c|c|c|c|}
\hline $\begin{array}{l}\text { Phytogenic } \\
\text { plant origin }\end{array}$ & $\begin{array}{l}\text { Supplemented } \\
\text { form }\end{array}$ & $\begin{array}{l}\text { Inclusion } \\
\text { dosage(s) } \\
\text { tested }\end{array}$ & $\begin{array}{l}\text { Period of } \\
\text { administration }\end{array}$ & $\begin{array}{l}\text { Main bioactive } \\
\text { components ( } \leq 3)\end{array}$ & Fish species & Performance & Mucosal parameters evaluation & Key benefits summary & Reference \\
\hline & & & & & & $\begin{array}{l}\text { against } S \text {. } \\
\text { agalactiae }\end{array}$ & & & \\
\hline $\begin{array}{l}\text { Shirazi } \\
\text { thyme } \\
\text { (Zataria } \\
\text { multiflora) }\end{array}$ & $\begin{array}{l}\text { Hydroalcoholic } \\
\text { extract }\end{array}$ & $2.0 \mathrm{~g} \mathrm{~kg}^{-1}$ & 56 days & Thymol and carvacrol? (N/) & $\begin{array}{l}\text { Rainbow trout } \\
\text { (Oncorhynchus } \\
\text { mykiss) }\end{array}$ & $\uparrow$ Survival rate & $\begin{array}{l}\uparrow \text { Skin mucus bactericidal activity } \\
\text { against } A \text {. hydrophila } \\
\uparrow \text { Skin mucus lysozyme activity }\end{array}$ & Increase skin mucosal immunity & $\begin{array}{l}\text { Mirghaed, Hoseini } \\
(79)\end{array}$ \\
\hline $\begin{array}{l}\text { Shirazi } \\
\text { thyme } \\
\text { (Zataria }\end{array}$ & $\begin{array}{l}\text { Powder }(1: 1) \\
+ \text { aflatoxin B1 }\end{array}$ & $\begin{array}{l}40 \mathrm{~g} \mathrm{~kg}^{-1} \\
\left(20 \mathrm{~g} \mathrm{~kg}^{-1}\right. \\
\text { each) }\end{array}$ & 12 weeks & $\mathrm{N} / \mathrm{I}$ & $\begin{array}{l}\text { Common carp } \\
\text { (Cyprinus carpio) }\end{array}$ & No effect & No effect & $\begin{array}{l}\text { Do not prevent intestinal tissue lesions } \\
\text { induced by aflatoxin B1 }\end{array}$ & Tasa, Imani (80) \\
\hline $\begin{array}{l}\text { multiflora) } \\
\text { + Rosemary } \\
\text { (Rosmarinus } \\
\text { officinalis) }\end{array}$ & & & & & & & & & \\
\hline $\begin{array}{l}\text { Rosemary } \\
\text { (Rosmarinus } \\
\text { officinalis) }\end{array}$ & Aqueous extract & $\begin{array}{l}10,20,40,80 \\
\text { and } 100 \mathrm{ml} / \\
100 \mathrm{~g}\end{array}$ & 20 days & 1,8-Cineole & $\begin{array}{l}\text { Common carp } \\
\text { (Cyprinus carpio) }\end{array}$ & $\mathrm{N} / \mathrm{I}$ & $\begin{array}{l}\text { 1 Skin mucus level of 1,8-Cineole } \\
\text { dose-dependent } \\
\text { No effect upon intestine } \\
\text { histopathology }\end{array}$ & $\begin{array}{l}\text { High volume of extracts might } \\
\text { promote hepatic toxicity }\end{array}$ & $\begin{array}{l}\text { Zoral, Ishikawa } \\
\text { (81) }\end{array}$ \\
\hline $\begin{array}{l}\text { Rosemary } \\
\text { (Rosmarinus } \\
\text { officinalis) }\end{array}$ & Powder & $\begin{array}{l}0.6,1.2,1.8 \\
\text { and } 2.4 \mathrm{~g} \mathrm{~kg}^{-1}\end{array}$ & 4 and 12 weeks & Carnosic acid and carnosol (1:1) & $\begin{array}{l}\text { Gilthead seabream } \\
\text { (Sparus aurata) }\end{array}$ & No effect & No effect & $\begin{array}{l}\text { The histological examination of the } \\
\text { intestine showed no aspects that } \\
\text { might pose problems for absorption, } \\
\text { or any immune system disorder } \\
\text { associated with the intestine }\end{array}$ & $\begin{array}{l}\text { Hernandez, Garcia } \\
\text { Garcia (82) }\end{array}$ \\
\hline $\begin{array}{l}\text { Oliveria } \\
\text { (Oliveria } \\
\text { decumbens) }\end{array}$ & $\begin{array}{l}\text { Essential oils and/ } \\
\text { or hydroethanolic } \\
\text { extract }\end{array}$ & $\begin{array}{l}0.01 \%, 0.1 \% \\
\text { and } 1.0 \%\end{array}$ & $\begin{array}{l}60 \text { days }+14 \\
\text { days S. iniae } \\
\text { challenge }\end{array}$ & $\begin{array}{l}\gamma \text {-terpinene, } \\
\text { carvacrol and thymol }\end{array}$ & $\begin{array}{l}\text { Nile tilapia } \\
\text { (Oreochromis } \\
\text { niloticus) }\end{array}$ & $\begin{array}{l}\text { } \uparrow \text { Survival } \\
\text { against } S \text {. iniae }\end{array}$ & No effect & $\begin{array}{l}\text { Increase fish survival } 14 \text { days after } \\
\text { challenge with S. iniae }\end{array}$ & $\begin{array}{l}\text { Vazirzadeh, Jalali } \\
\text { (83) }\end{array}$ \\
\hline $\begin{array}{l}\text { Clove basil } \\
\text { (Ocimum } \\
\text { gratissimum) }\end{array}$ & Ethanolic extract & $\begin{array}{l}5.0,10.0, \text { and } \\
15.0 \mathrm{~g} \mathrm{~kg}^{-1}\end{array}$ & $\begin{array}{l}12 \text { weeks }+14 \\
\text { days } L \text {. } \\
\text { monocytogenes } \\
\text { challenge }\end{array}$ & $\mathrm{N} / \mathrm{I}$ & $\begin{array}{l}\text { African cattish } \\
\text { (Clarias gariepinus) }\end{array}$ & $\begin{array}{l}\uparrow \text { final weight } \\
\uparrow \text { weight gain } \\
\uparrow \text { SGR } \\
\uparrow \text { Feed intake } \\
\uparrow \text { survival } \\
\text { against L. } \\
\text { monocytogenes }\end{array}$ & $\begin{array}{l}\uparrow \text { intestine villus length } \\
\uparrow \text { intestine villus width } \\
\uparrow \text { intestine absorption area }\end{array}$ & $\begin{array}{l}\text { Improve the fish performance, health, } \\
\text { and immune response }\end{array}$ & $\begin{array}{l}\text { Abdel-Tawwab, } \\
\text { Adeshina (84) }\end{array}$ \\
\hline $\begin{array}{l}\text { Clove basil } \\
\text { (Ocimum } \\
\text { gratissimum) }\end{array}$ & Essential oils & $\begin{array}{l}0.5 \%, 1.0 \% \\
\text { and } 1.5 \%\end{array}$ & $\begin{array}{l}55 \text { days }+10 \\
\text { days } S . \\
\text { agalactiae } \\
\text { challenge }\end{array}$ & $\begin{array}{l}\text { 1,8-cineole, eugenol and } \beta \text { - } \\
\text { selinene }\end{array}$ & $\begin{array}{l}\text { Nile tilapia } \\
\text { (Oreochromis } \\
\text { niloticus) }\end{array}$ & $\mathrm{N} / \mathrm{l}$ & $\begin{array}{l}\uparrow \text { Intestine villus height } \\
\uparrow \text { Intestine goblet cells number } \\
\downarrow \text { Gill epithelial detachment in the } \\
\text { secondary lamellae } \\
\downarrow \text { Gill congestion at the base of the } \\
\text { secondary lamellae }\end{array}$ & $\begin{array}{l}\text { Ameliorate tissue damages, even in } \\
\text { situations of infection }\end{array}$ & $\begin{array}{l}\text { Brum, Cardoso } \\
\text { (85) }\end{array}$ \\
\hline $\begin{array}{l}\text { American } \\
\text { basil } \\
\text { (Ocimum } \\
\text { americanum) }\end{array}$ & Essential oils & $\begin{array}{l}0.25,0.5,1.0 \\
\text { and } 2.0 \mathrm{~g} \mathrm{~kg}^{-1}\end{array}$ & 7 weeks & Linalool, eugenol and 1,8-cineole & $\begin{array}{l}\text { Red drum } \\
\text { (Sciaenops } \\
\text { ocellatus) }\end{array}$ & No effect & $\begin{array}{l}\uparrow \text { Stomach lysozyme activity } \\
\text { No effect upon the intestinal microbial } \\
\text { community }\end{array}$ & $\begin{array}{l}\text { Different supplementation levels do not } \\
\text { influence growth performance and } \\
\text { intestinal microbial community; } \\
\text { however, show effects on } \\
\text { immunological responses }\end{array}$ & $\begin{array}{l}\text { Sutili, Velasquez } \\
\text { (86) }\end{array}$ \\
\hline $\begin{array}{l}\text { Savory } \\
\text { (Satureja } \\
\text { khuzestanica) }\end{array}$ & Powder & $1 \%$ & 45 days & $\mathrm{N} / \mathrm{I}$ & $\begin{array}{l}\text { Common carp } \\
\text { (Cyprinus carpio) }\end{array}$ & $\mathrm{N} / \mathrm{l}$ & $\uparrow$ Intestinal lactic acid bacteria & Improves intestinal health & $\begin{array}{l}\text { Mousavi, } \\
\text { Mohammadiazarm } \\
\text { (87) }\end{array}$ \\
\hline $\begin{array}{l}\text { Allium sp. } \\
\text { Garlic }\end{array}$ & Aqueous extract & $0.10,0.15$, and & 80 days & $\mathrm{N} / \mathrm{l}$ & Guppy (Poecilia & No effect & $\uparrow$ Skin mucus lysozyme & & Motlag, Safari (88) \\
\hline $\begin{array}{l}\text { (Allium } \\
\text { sativum) }\end{array}$ & & $0.20 \mathrm{ml} \mathrm{kg}^{-1}$ & & & reticulata) & & $\begin{array}{l}\uparrow \text { Skin mucus alternative complement } \\
\uparrow \text { Skin mucus total Ig } \\
\uparrow \text { Skin mucus alkaline phosphatase }\end{array}$ & $\begin{array}{l}\text { extract per kg feed is suggested to } \\
\text { obtain optimal skin mucus immunity }\end{array}$ & \\
\hline $\begin{array}{l}\text { Garlic } \\
\text { (Allium } \\
\text { sativum) }\end{array}$ & Oil & $50 \mu \mathrm{kg}^{-1}$ & $\begin{array}{l}28 \text { days }+ \\
\text { exposure to } \\
\text { silver } \\
\text { nanoparticles }\end{array}$ & $\mathrm{N} / \mathrm{I}$ & Rohu (Labeo rohita) & $\mathrm{N} / \mathrm{I}$ & $\begin{array}{l}1 \text { Gill oxidative stress enzymes activity } \\
\downarrow \text { Gill histopathologic lesions }\end{array}$ & $\begin{array}{l}\text { Amelioration of silver nanoparticles- } \\
\text { induced oxidative stress and } \\
\text { histoprotective effects }\end{array}$ & Khan, Qureshi (89) \\
\hline $\begin{array}{l}\text { Garlic } \\
\text { (Allium } \\
\text { sativum) }\end{array}$ & Powder & $\begin{array}{l}0.5 \mathrm{~g} \text { and } 1.0 \\
\mathrm{~g} / 100 \mathrm{~g}\end{array}$ & $\begin{array}{l}2 \text { months }+ \\
2 \text { weeks S. iniae } \\
\text { challenge }\end{array}$ & $\mathrm{N} / \mathrm{l}$ & $\begin{array}{l}\text { Nile tilapia } \\
\text { (Oreochromis } \\
\text { niloticus) }\end{array}$ & $\begin{array}{l}\uparrow \text { Survival } \\
\text { against } S \text {. iniae }\end{array}$ & $\begin{array}{l}\uparrow \text { Anterior intestine transcriptional } \\
\text { levels of interleukin genes (IL-10 and } \\
\text { IL-17F) } \\
\uparrow \text { OOU counts for the phylum of } \\
\text { Proteobacteria and Tenericutes }\end{array}$ & $\begin{array}{l}\text { Could be effective in the prevention of } \\
\text { S. iniae infection in fish }\end{array}$ & Foysal, Alam (90) \\
\hline $\begin{array}{l}\text { Garlic } \\
\text { (Allium } \\
\text { sativum) }\end{array}$ & Powder & $\begin{array}{l}5.0 \%, 10.0 \% \\
\text { and } 20.0 \%\end{array}$ & $\begin{array}{l}14 \text { or } 28 \text { or } 32 \\
\text { days }+C \text {. } \\
\text { irritans challenge }\end{array}$ & Allicin $(1.25 \mathrm{mg} / \mathrm{g})$ & $\begin{array}{l}\text { Guppy (Poecilia } \\
\text { reticulata) }\end{array}$ & $\begin{array}{l}\downarrow \uparrow \text { Gills and } \\
\text { caudal fin C. } \\
\text { irritans infection }\end{array}$ & $\mathrm{N} / \mathrm{l}$ & $\begin{array}{l}\text { No clear preventative effect against } C \text {. } \\
\text { irritans }\end{array}$ & Kim, Fridman (91) \\
\hline
\end{tabular}


TABLE 1 | Continued

\begin{tabular}{|c|c|c|c|c|c|c|c|c|c|}
\hline $\begin{array}{l}\text { Phytogenic } \\
\text { plant origin }\end{array}$ & $\begin{array}{l}\text { Supplemented } \\
\text { form }\end{array}$ & $\begin{array}{l}\text { Inclusion } \\
\text { dosage(s) } \\
\text { tested }\end{array}$ & $\begin{array}{c}\text { Period of } \\
\text { administration }\end{array}$ & $\begin{array}{l}\text { Main bioactive } \\
\text { components }(\leq 3)\end{array}$ & Fish species & Performance & Mucosal parameters evaluation & Key benefits summary & Reference \\
\hline $\begin{array}{l}\text { Garlic } \\
\text { (Allium } \\
\text { sativum) }\end{array}$ & Powder & $\begin{array}{l}1.0 \%, 1.5 \% \\
\text { and } 2.0 \%\end{array}$ & 120 days & & $\begin{array}{l}\text { Rainbow trout } \\
\text { (Oncorhynchus } \\
\text { mykiss) }\end{array}$ & $\begin{array}{l}\uparrow \text { Weight gain } \\
\uparrow \text { SGR }\end{array}$ & $\begin{array}{l}\downarrow \text { Bacterial diversity and richness } \\
\uparrow \text { Deefgea, Mycoplasma, } \\
\text { Exiguobacterium and Clostridium } \\
\text { genera } \\
\downarrow \uparrow \text { Aeromonas genus }\end{array}$ & $\begin{array}{l}\text { Beneficial in terms of promoting } \\
\text { growth and inducing changes in the } \\
\text { intestinal microbiota in a dose- } \\
\text { dependent manner }\end{array}$ & $\begin{array}{l}\text { Büyükdeveci, } \\
\text { Balcázar (92) }\end{array}$ \\
\hline $\begin{array}{l}\text { Garlic } \\
\text { (Allium } \\
\text { sativum) }\end{array}$ & Powder & $\begin{array}{l}5.0,10.0 \text { and } \\
15.0 \mathrm{~g} \mathrm{~kg}^{-1} \\
\quad \text { diet }\end{array}$ & 8 weeks & $\mathrm{N} / \mathrm{I}$ & $\begin{array}{l}\text { Caspian roach } \\
\text { (Rutilus rutilus) }\end{array}$ & $\begin{array}{l}\uparrow \text { Weight } \\
\uparrow \text { Growth rate }\end{array}$ & $\begin{array}{l}\uparrow \text { Skin mucus antibacterial activity } \\
\text { against } S \text {. faecium, } M \text {. lluteus, } S \text {. } \\
\text { marcescens and } E \text {. coli } \\
\uparrow \text { Skin mucus protein level } \\
\uparrow \text { Skin mucus alkaline phosphatase } \\
\text { activity }\end{array}$ & $\begin{array}{l}\text { Beneficially affects the skin mucus } \\
\text { immune parameters and growth } \\
\text { performance }\end{array}$ & $\begin{array}{l}\text { Ghehdarijani, } \\
\text { Hajimoradloo (93) }\end{array}$ \\
\hline $\begin{array}{l}\text { Garlic } \\
\text { (Allium } \\
\text { sativum) }\end{array}$ & Lyophilized & $2.0 \%$ & $\begin{array}{l}21 \text { days + } \\
\text { cadmium } \\
\text { exposure }\end{array}$ & $\mathrm{N} / \mathrm{I}$ & $\begin{array}{l}\text { Prussian carp } \\
\text { (Carassius gibelio) }\end{array}$ & $\mathrm{N} / \mathrm{I}$ & $\downarrow$ Gill histopathologic lesions & $\begin{array}{l}\text { Shows chelating and antioxidant } \\
\text { potential }\end{array}$ & $\begin{array}{l}\text { Nicula, Dumitrescu } \\
\text { (94) }\end{array}$ \\
\hline $\begin{array}{l}\text { Onion (Allium } \\
\text { cepa) }\end{array}$ & Powder & $1 \%$ & 45 days & $\mathrm{N} / \mathrm{I}$ & $\begin{array}{l}\text { Common carp } \\
\text { (Cyprinus carpio) }\end{array}$ & $\mathrm{N} / \mathrm{I}$ & $\uparrow$ Intestinal lactic acid bacteria & Improves intestinal health & $\begin{array}{l}\text { Mousavi, } \\
\text { Mohammadiazarm } \\
\text { (87) }\end{array}$ \\
\hline $\begin{array}{l}\text { Onion (Allium } \\
\text { cepa) }\end{array}$ & Ethanolic extract & $\begin{array}{l}0.5 \%, 1.0 \% \\
1.5 \% \text { and } \\
2.0 \%\end{array}$ & 12 weeks & $\mathrm{N} / \mathrm{l}$ & $\begin{array}{l}\text { African sharptooth } \\
\text { catfish (Clarias } \\
\text { gariepinus) }\end{array}$ & No effect & $\begin{array}{l}\downarrow \text { Intestine villus length } \\
\uparrow \text { Intestine villus width } \\
\uparrow \text { Intestine absorption area } \\
\uparrow \text { Intestine cryptal depth }\end{array}$ & $\begin{array}{l}\text { Increase the digestive and absorptive } \\
\text { capacity of the intestine }\end{array}$ & Bello, Emikpe (95) \\
\hline $\begin{array}{l}\text { Mongolian } \\
\text { Wild Onion } \\
\text { (Allium } \\
\text { mongolicum) }\end{array}$ & Ethanolic extract & $0.04 \mathrm{~g} \mathrm{~kg}^{-1}$ & $\begin{array}{l}4 \text { weeks }+ \\
\text { chromium }(\mathrm{Cr}) \\
\text { exposure }\end{array}$ & Flavonoids $\geq 90 \%$ (HPLC) & $\begin{array}{l}\text { Grass carp } \\
\text { (Ctenopharyngodon } \\
\text { idella) }\end{array}$ & $\mathrm{N} / \mathrm{I}$ & $\begin{array}{l}\downarrow \text { Intestine and gill Cr accumulation } \\
\downarrow \text { Gill malondiaidehyde content } \\
\downarrow \text { Gill protein carbonyl content } \\
\uparrow \text { Intestine lysozyme activity } \\
\uparrow \text { Intestine complement } 3 \text { levels } \\
\uparrow \text { Intestine and gill tight junction } \\
\text { proteins gene expression } \\
\uparrow \downarrow \text { ntestine and gill NF-- } \\
\text { path signaling } \\
\text { pathway gene expression }\end{array}$ & $\begin{array}{l}\text { Decrease in Cr-accumulation, } \\
\text { oxidative stress, immunosuppression } \\
\text { and inflammatory response following } \\
\text { Cr exposure }\end{array}$ & Zhao, Yuan (96) \\
\hline $\begin{array}{l}\text { Thyme } \\
\text { (Thymus } \\
\text { vulgaris) }\end{array}$ & Ethanolic solution & $\begin{array}{l}0.15,0.3,0.45, \\
0.6,0.75 \mathrm{~g} \mathrm{~kg}^{-}\end{array}$ & $\begin{array}{l}56 \text { days }+14 \\
\text { days } A \text {. veronii } \\
\text { challenge }\end{array}$ & Thymol (commercial product) & $\begin{array}{l}\text { Snakehead fish } \\
\text { (Channa argus) }\end{array}$ & $\begin{array}{l}\uparrow \text { Final weight } \\
\uparrow \text { Weight gain } \\
\uparrow \text { SGR } \\
\uparrow \text { Protein } \\
\text { efficiency ratio } \\
\downarrow \text { FCR } \\
\uparrow \text { Survival to } A \text {. } \\
\text { veronii }\end{array}$ & $\begin{array}{l}\uparrow \text { Intestine SOD, CAT, GSH-Px } \\
\text { activities } \\
\downarrow \text { Intestine malondialdehyde content } \\
\uparrow \text { IL-10 and TGF-b gene expression in } \\
\text { intestine } \\
\downarrow \text { HSP70, TNF-a, IL-1b and IL-8 gene } \\
\text { expression in intestine }\end{array}$ & $\begin{array}{l}\text { Adequate dietary supplementation can } \\
\text { effectively enhance the growth, } \\
\text { antioxidant status, immune response } \\
\text { and disease resistance }\end{array}$ & Kong, Li (97) \\
\hline $\begin{array}{l}\text { Thyme } \\
\text { (Thymus }^{*} \\
\text { vulgaris) }\end{array}$ & $\mathrm{N} / \mathrm{I}$ & $\begin{array}{l}0.1,0.2 \text { and } \\
0.3 \mathrm{~g} \mathrm{~kg}^{-1}\end{array}$ & $\begin{array}{l}60 \text { days }+8 \\
\text { days } A \text {. } \\
\text { hydrophila } \\
\text { challenge }\end{array}$ & Thymol (commercial product) & $\begin{array}{l}\text { Grass carp } \\
\text { (Ctenopharyngodon } \\
\text { idella) }\end{array}$ & $\begin{array}{l}\uparrow \text { Final weight } \\
\uparrow \text { Sunvival } \\
\text { against } A \text {. } \\
\text { hydrophila }\end{array}$ & $\begin{array}{l}\uparrow \text { Gill enzymes of the phosphotransfer } \\
\text { network: cytosolic and mitochondrial } \\
\text { creatine kinases, adenylate kinase } \\
\text { activities and ATP levels in infected } \\
\text { fish } \\
\downarrow \text { Gill ROS levels in infected fish }\end{array}$ & $\begin{array}{l}\text { Favors weight gain and fish longevity. } \\
\text { Prevents } A \text {. hydrophila induced } \\
\text { branchial bioenergetics. High } \\
\text { concentrations deserve attention } \\
\text { because of side-effects }\end{array}$ & $\begin{array}{l}\text { Morselli, Baldissera } \\
\text { (98) }\end{array}$ \\
\hline $\begin{array}{l}\text { Thyme } \\
\text { (Thymus }^{*} \\
\text { vulgaris) }\end{array}$ & Crystals & $0.5 \mathrm{~g} \mathrm{~kg}^{-1}$ & 70 days & $\begin{array}{l}\text { Thymol (99\% purity; commercial } \\
\text { product) }\end{array}$ & $\begin{array}{l}\text { Nile tilapia } \\
\text { (Oreochromis } \\
\text { niloticus) }\end{array}$ & $\begin{array}{l}\uparrow S G R \\
\uparrow \text { Protein } \\
\text { efficiency ratio }\end{array}$ & $\begin{array}{l}\downarrow \text { Intestine total aerobic and anaerobic } \\
\text { counts }\end{array}$ & $\begin{array}{l}\text { Improve some performance } \\
\text { parameters and negatively modulates } \\
\text { intestinal microbial communities. } \\
\text { Demonstrates a notable synergistic } \\
\text { interaction with chitosan nanoparticle } \\
\text { with beneficial effects }\end{array}$ & $\begin{array}{l}\text { El-Naby, Al- } \\
\text { Sagheer (99) }\end{array}$ \\
\hline 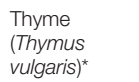 & $\mathrm{N} / \mathrm{I}$ & $1.0 \mathrm{~g} \mathrm{~kg}^{-1}$ & 56 days & Thymol (commercial product) & $\begin{array}{l}\text { Rainbow trout } \\
\text { (Oncorhynchus } \\
\text { mykiss) }\end{array}$ & $\downarrow F C R$ & $\begin{array}{l}\downarrow \text { Intestine culturable anaerobe } \\
\text { bacteria }\end{array}$ & $\begin{array}{l}\text { Modulated intestinal microbial } \\
\text { communities disfavoring total } \\
\text { anaerobes }\end{array}$ & $\begin{array}{l}\text { Giannenas, } \\
\text { Triantafillou (100) }\end{array}$ \\
\hline $\begin{array}{l}\text { Oregano } \\
\left.\text { (Origanum }_{\text {vulgare }}\right)^{*}\end{array}$ & $\mathrm{~N} / \mathrm{I}$ & $1.0 \mathrm{~g} \mathrm{~kg}^{-1}$ & 56 days & Carvacrol (commercial product) & $\begin{array}{l}\text { Rainbow trout } \\
\text { (Oncorhynchus } \\
\text { mykiss) }\end{array}$ & $\downarrow F C R$ & $\begin{array}{l}\downarrow \text { Intestine culturable anaerobe } \\
\text { bacteria }\end{array}$ & $\begin{array}{l}\text { Modulated intestinal microbial } \\
\text { communities disfavoring total } \\
\text { anaerobes }\end{array}$ & $\begin{array}{l}\text { Giannenas, } \\
\text { Triantafillou (100) }\end{array}$ \\
\hline $\begin{array}{l}\text { Chinese } \\
\text { skullcap } \\
\text { (Scutellaria } \\
\text { baicalensis) }^{*}\end{array}$ & Powder & $\begin{array}{l}0.4,0.8 \text { and } \\
1.6 \mathrm{~g} \mathrm{~kg}^{-1}\end{array}$ & $\begin{array}{l}60 \text { days }+\mathrm{H}_{2} \mathrm{O}_{2} \\
\text { challenge }\end{array}$ & $\begin{array}{l}\text { Baicalin (80\% purity, commercial } \\
\text { product) }\end{array}$ & $\begin{array}{l}\text { Nile tilapia } \\
\text { (Oreochromis } \\
\text { niloticus) }\end{array}$ & $\downarrow F C R$ & $\begin{array}{l}\uparrow \text { Gill glutathione level } \\
\uparrow \text { Gill total antioxidant capacity }\end{array}$ & $\begin{array}{l}\text { Improves feed efficiency, enhance } \\
\text { antioxidative ability and alleviate } \\
\text { oxidative stress }\end{array}$ & Jia, Du (101) \\
\hline $\begin{array}{l}\text { Garlic } \\
(\text { Allium } \\
\text { sativum) })^{*}\end{array}$ & Liquid & $\begin{array}{l}0.005 \% \text {, } \\
0.01 \% \text { and } \\
0.02 \%\end{array}$ & 30 days & $\begin{array}{l}\text { Allicin (98\% purity, commercial } \\
\text { product) }\end{array}$ & $\begin{array}{l}\text { Large yellow } \\
\text { croaker }\end{array}$ & $\begin{array}{l}\uparrow \text { Final weight } \\
\uparrow \text { Final length }\end{array}$ & $\begin{array}{l}\uparrow \text { Intestine total antioxidant capacity } \\
\uparrow \text { Intestine antioxidant enzymes (CAT, } \\
\text { NO and NOS) activity }\end{array}$ & $\begin{array}{l}\text { Improve the survival and growth of } \\
\text { large yellow croaker larvae probably } \\
\text { by promoting intestinal development, }\end{array}$ & Huang, Yao (102) \\
\hline
\end{tabular}

Single bioactive compoun (Thyr $0.15,0.3,0.45, \quad 56$ days +14 
TABLE 1 | Continued

\begin{tabular}{|c|c|c|c|c|c|c|c|c|c|}
\hline $\begin{array}{l}\text { Phytogenic } \\
\text { plant origin }\end{array}$ & $\begin{array}{l}\text { Supplemented } \\
\text { form }\end{array}$ & $\begin{array}{l}\text { Inclusion } \\
\text { dosage(s) } \\
\text { tested }\end{array}$ & $\begin{array}{c}\text { Period of } \\
\text { administration }\end{array}$ & $\begin{array}{l}\text { Main bioactive } \\
\text { components }(\leq 3)\end{array}$ & Fish species & Performance & Mucosal parameters evaluation & Key benefits summary & Reference \\
\hline & & & & & $\begin{array}{l}\text { (Larimichthys } \\
\text { crocea) }\end{array}$ & $\begin{array}{l}\uparrow \text { SGR } \\
\uparrow \text { survival rate }\end{array}$ & $\begin{array}{l}\downarrow \text { Intestine transcriptional levels of pro- } \\
\text { inflammatory genes }\end{array}$ & $\begin{array}{l}\text { alleviating inflammation and enhancing } \\
\text { appetite }\end{array}$ & \\
\hline \multicolumn{10}{|c|}{ Phytogenics combinations } \\
\hline $\begin{array}{l}\text { Phytogenics } \\
\text { combination }\end{array}$ & Essential oils & 200 ppm & $\begin{array}{l}70 \text { days }+15 \\
\text { days N. girellae } \\
\text { challenge }\end{array}$ & $\begin{array}{l}\text { Garlic and Lamiaceae-plants oils } \\
\text { (N/;; commercial additive) }\end{array}$ & $\begin{array}{l}\text { Greater amberjack } \\
\text { (Seriola dumerill) }\end{array}$ & No effect & $\begin{array}{l}\uparrow \text { Skin mucus lysozyme activity } 15 \\
\text { days post } N \text {. girellae challenge } \\
\uparrow \text { Piscidin gene expression in skin pre- } \\
\text { challenge } \\
\uparrow \text { Proinflammatory cytokines (tnf- } \alpha \\
\text { and il1- }- \text { ), AMPs (hep and cath), } \\
\text { immunoglobulin (IgT), complement } \\
\text { protein (c3) T-cells marker (cd8) and } \\
\text { mucin (muc-2) gene expression in skin } \\
\text { post-challenge } \\
\downarrow \text { Casp3 gene expression in skin post- } \\
\text { challenge }\end{array}$ & $\begin{array}{l}\text { Facilitates the immunological response } \\
\text { of skin once the parasite is fixed, } \\
\text { generating a hostile microenvironment } \\
\text { in skin and lowering the parasite load }\end{array}$ & $\begin{array}{l}\text { Fernández- } \\
\text { Montero, } \\
\text { Torrecillas (16) }\end{array}$ \\
\hline $\begin{array}{l}\text { Phytogenics } \\
\text { combination }\end{array}$ & Essential oils & $0.3 \mathrm{~g} \mathrm{~kg}^{-1}$ & $\begin{array}{l}8 \text { weeks }+2 \\
\text { weeks hypoxia } \\
\text { challenge } \\
\text { (Total } 10 \text { weeks) }\end{array}$ & $\begin{array}{l}\text { Cinnamaldehyde, thymol and } \\
\text { carvacrol }\end{array}$ & $\begin{array}{l}\text { Nile tilapia } \\
\text { (Oreochromis } \\
\text { niloticus) }\end{array}$ & $\begin{array}{l}\stackrel{\downarrow}{ } \\
\text { Hepatosomatic } \\
\text { index }\end{array}$ & $\begin{array}{l}\uparrow \text { Intestine villi density } \\
\downarrow \text { Intestine malondialdehyde content }\end{array}$ & $\begin{array}{l}\text { Positive effects of digestion and } \\
\text { antioxidative capacity }\end{array}$ & Ning, Zhang (103) \\
\hline $\begin{array}{l}\text { Phytogenics } \\
\text { combination }\end{array}$ & $\begin{array}{l}\text { Microencapsulated } \\
\text { essential oils }\end{array}$ & $0.5 \%$ & 65 days & $\begin{array}{l}\text { Garlic essential oil (N/I), carvacrol } \\
\text { and thymol } \\
\text { (Commercial additive) }\end{array}$ & $\begin{array}{l}\text { Gilthead seabream } \\
\text { (Sparus aurata) }\end{array}$ & No effect & $\begin{array}{l}\uparrow \text { Skin mucus inhibitory activity against } \\
V \text {. anguillarum and P. anguilliseptica } \\
\downarrow \text { Cortisol in skin mucus } \\
\uparrow \text { Regulation of genes associated to } \\
\text { the secretory pathway in skin } \\
\uparrow \text { Regulation of genes associated to } \\
\text { non-specific immune response in skin } \\
\uparrow \text { Regulation of genes coding for } \\
\text { oxidative stress enzymes in skin }\end{array}$ & $\begin{array}{l}\text { Beneficially affects the skin and mucus } \\
\text { immune and stress parameters, } \\
\text { suggesting the stimulation and } \\
\text { recruitment of phagocytic cells and a } \\
\text { reduction in the fish allostatic load }\end{array}$ & $\begin{array}{l}\text { Firmino, } \\
\text { Fernández-Alacid } \\
\text { (14) }\end{array}$ \\
\hline $\begin{array}{l}\text { Phytogenics } \\
\text { combination }\end{array}$ & $\begin{array}{l}\text { Microencapsulated } \\
\text { essential oils }\end{array}$ & $0.5 \%$ & 65 days & $\begin{array}{l}\text { Garlic essential oil (N/I), carvacrol } \\
\text { and thymol } \\
\text { (Commercial additive) }\end{array}$ & $\begin{array}{l}\text { Gitthead seabream } \\
\text { (Sparus aurata) }\end{array}$ & No effect & $\begin{array}{l}\uparrow \text { Regulation of genes related to } \\
\text { processes of proteolysis and } \\
\text { inflammatory modulation, immunity, } \\
\text { transport and secretion, response to } \\
\text { cyclic compounds, symbiosis, and } \\
\text { RNA metabolism in the mid-anterior } \\
\text { intestine } \\
\text { No effect upon alpha diversity of } \\
\text { bacterial communities in the anterior } \\
\text { and posterior intestinal tract sections } \\
\downarrow \text { Spirochaetes phylum in the posterior } \\
\text { intestine } \\
\uparrow \text { Photobacterium and } \\
\text { Corynebacterium genera in the } \\
\text { anterior intestine } \\
\downarrow \text { Comamonos in the anterior intestine, } \\
\text { and Paracoccus, Prevotella and } \\
\text { Rothia genera in the posterior intestine } \\
\downarrow \text { Bacterial sequences related to } \\
\text { carbohydrate and drug metabolisms, } \\
\text { and membrane transport } \\
\uparrow \text { Bacterial sequences related to } \\
\text { glutathione and lipid metabolisms, } \\
\text { naphthalene degradation and sulphur } \\
\text { relay system } \\
\text { Evidence of host-microbial co- } \\
\text { metabolism }\end{array}$ & $\begin{array}{l}\text { The activation of leukocytes and } \\
\text { crosstalk between gut and microbiota } \\
\text { are suggested to regulate the } \\
\text { inflammatory response induced by the } \\
\text { additive }\end{array}$ & $\begin{array}{l}\text { Firmino, Vallejos- } \\
\text { Vidal (12) }\end{array}$ \\
\hline $\begin{array}{l}\text { Phytogenics } \\
\text { combination }\end{array}$ & $\begin{array}{l}\text { Microencapsulated } \\
\text { essential oils }\end{array}$ & $0.5 \%$ & $\begin{array}{l}65 \text { days }+39 \\
\text { days } S . \\
\text { chrysophrii }\end{array}$ & $\begin{array}{l}\text { Garlic essential oil (N/I), carvacrol } \\
\text { and thymol } \\
\text { (Commercial additive) }\end{array}$ & $\begin{array}{l}\text { Gilthead seabream } \\
\text { (Sparus aurata) }\end{array}$ & $\begin{array}{l}\downarrow S \text {. } \\
\text { chrysophrii total } \\
\text { parasitation }\end{array}$ & $\begin{array}{l}\text { T Regulation of genes related pro- } \\
\text { inflammatory immune response } \\
\text { arbitrated by degranulating acidophilic } \\
\text { granulocytes, sustained by antioxidant }\end{array}$ & $\begin{array}{l}\text { Promotes gill mucosal immunity and } \\
\text { reduces gill ectoparasite incidence }\end{array}$ & $\begin{array}{l}\text { Firmino, Vallejos- } \\
\text { Vidal (15) }\end{array}$ \\
\hline
\end{tabular}




\begin{tabular}{|c|c|c|c|c|c|c|c|c|c|}
\hline $\begin{array}{l}\text { Phytogenic } \\
\text { plant origin }\end{array}$ & $\begin{array}{l}\text { Supplemented } \\
\text { form }\end{array}$ & $\begin{array}{l}\text { Inclusion } \\
\text { dosage(s) } \\
\text { tested }\end{array}$ & $\begin{array}{c}\text { Period of } \\
\text { administration }\end{array}$ & $\begin{array}{l}\text { Main bioactive } \\
\text { components ( } \leq 3)\end{array}$ & Fish species & Performance & Mucosal parameters evaluation & Key benefits summary & Reference \\
\hline & & & $\begin{array}{l}\text { challenge (total } \\
104 \text { days) }\end{array}$ & & & & $\begin{array}{l}\text { and anti-inflammatory responses in } \\
\text { gills } \\
\uparrow \text { Carboxylate glycoproteins containing } \\
\text { sialic acid in mucous and } \\
\text { epithelial gill's cells }\end{array}$ & & \\
\hline $\begin{array}{l}\text { Phytogenics } \\
\text { combination }\end{array}$ & Essential oils & $0.02 \%$ & $\begin{array}{l}9 \text { weeks }+1 \\
\text { week stress and } \\
\text { V. anguillarum } \\
\text { challenge }\end{array}$ & $\begin{array}{l}\text { Garlic and Lamiaceae-plants oils } \\
\text { (N//; commercial additive) }\end{array}$ & $\begin{array}{l}\text { European sea bass } \\
\text { (Dicentrarchus } \\
\text { labrax) }\end{array}$ & $\begin{array}{l}\uparrow \text { Survival } \\
\text { against Vibrio } \\
\text { anguillarum } \\
\text { when stress- } \\
\text { challenged }\end{array}$ & $\begin{array}{l}\text { 1 Skin mucus lysozyme activity when } \\
\text { stress and bacterial challenge }\end{array}$ & $\begin{array}{l}\text { Attenuate the fish physiological } \\
\text { response to stress increasing } \\
\text { resistance to Vibrio anguillarum } \\
\text { infection }\end{array}$ & $\begin{array}{l}\text { Serradell, } \\
\text { Torrecillas (104) }\end{array}$ \\
\hline $\begin{array}{l}\text { Phytogenics } \\
\text { combination }\end{array}$ & Essential oils & $0.02 \%$ & 63 days & $\begin{array}{l}\text { Garlic and Lamiaceae-plants oils } \\
\text { (N//; commercial additive) }\end{array}$ & $\begin{array}{l}\text { European sea bass } \\
\text { (Dicentrarchus } \\
\text { labrax) }\end{array}$ & No effect & $\begin{array}{l}\downarrow \text { Shannon alpha diversity of mucosa- } \\
\text { associated microbiota } \\
\uparrow \text { Clostridiales order in intestinal } \\
\text { content } \\
\downarrow \text { Coliforms and Vibrionales } \\
\text { allochthonous microbiota }\end{array}$ & $\begin{array}{l}\text { Reduction of orders containing } \\
\text { potentially pathogenic species for fish, } \\
\text { and enrichment of gut microbiota } \\
\text { composition with butyrate producer } \\
\text { taxa }\end{array}$ & $\begin{array}{l}\text { Rimoldi, Torrecillas } \\
\text { (105) }\end{array}$ \\
\hline $\begin{array}{l}\text { Phytogenics } \\
\text { combination }\end{array}$ & Essential oils & 200 ppm & $\begin{array}{l}63 \text { days }+7 \\
\text { days stress and } \\
V \text {. anguillarum } \\
\text { challenge }\end{array}$ & $\begin{array}{l}\text { Garlic and Lamiaceae-plants oils } \\
\text { (N//; commercial additive) }\end{array}$ & $\begin{array}{l}\text { European sea bass } \\
\text { (Dicentrarchus } \\
\text { labrax) }\end{array}$ & No effect & $\begin{array}{l}\downarrow \text { Posterior intestine fold area covered } \\
\text { by goblet cells } \\
\downarrow \text { Posterior intestine goblet cells area } \\
\uparrow \text { Intestine mucus coverage post- } \\
\text { challenge }\end{array}$ & $\begin{array}{l}\text { Protective effect focused mainly on the } \\
\text { preileorectal valve region }\end{array}$ & $\begin{array}{l}\text { Torrecillas, Terova } \\
\text { (13) }\end{array}$ \\
\hline $\begin{array}{l}\text { Phytogenics } \\
\text { combination }\end{array}$ & $\mathrm{N} / \mathrm{l}$ extract & $6.0 \mathrm{~g} \mathrm{~kg}^{-1}$ & $\begin{array}{l}30 \text { days }+10 \\
\text { days crowding } \\
\text { stress }(40 \text { days } \\
\text { total) }\end{array}$ & $\begin{array}{l}\text { Saint John's wort (Hypericum } \\
\text { perforatum, Hypericacea), lemon } \\
\text { balm (Melissa officinalis, } \\
\text { Lamiaceae) and rosemary } \\
\text { (Rosmarinus officinalis, } \\
\text { Lamiaceae) mixed at a ratio 3:2:1 }\end{array}$ & $\begin{array}{l}\text { Atlantic salmon } \\
\text { (Salmo salar) }\end{array}$ & No effect & $\downarrow$ Gut lipid peroxidation & Improves the gut antioxidant status & $\begin{array}{l}\text { Reyes-Cerpa, } \\
\text { Vallejos-Vidal (106) }\end{array}$ \\
\hline $\begin{array}{l}\text { Phytogenics } \\
\text { combination }\end{array}$ & Powder & $1 \%$ & 45 days & $\begin{array}{l}\text { Savory (Satureja khuzestanica, } \\
\text { Lamiaceae) } 0.5 \% \text { and Onion } \\
\text { (Allium cepa, Alliaceae) } 0.5 \%\end{array}$ & $\begin{array}{l}\text { Common carp } \\
\text { (Cyprinus carpio) }\end{array}$ & $\mathrm{N} / \mathrm{I}$ & $\uparrow$ Intestinal lactic acid bacteria & Improves intestinal health & $\begin{array}{l}\text { Mousavi, } \\
\text { Mohammadiazarm } \\
\text { (87) }\end{array}$ \\
\hline $\begin{array}{l}\text { Phytogenics } \\
\text { combination }\end{array}$ & Essential oils & $\begin{array}{l}0.06,0.2,0.4 \\
\text { and } 0.8 \mathrm{~g} \mathrm{~kg}^{-1}\end{array}$ & 6 weeks & $\begin{array}{l}\text { Thymol and carvacrol (1:1; } \\
\text { commercial additive) }\end{array}$ & $\begin{array}{l}\text { Hybrid tilapia }(\mathrm{O} \text {. } \\
\text { niloticus o } \times O \text {. } \\
\text { aureus of }\end{array}$ & $\mathrm{N} / \mathrm{l}$ & $\begin{array}{l}\uparrow \text { Posterior intestine villus height } \\
\uparrow \text { Posterior intestine goblet cell count } \\
\text { per villus } \\
\uparrow \text { Anterior intestine intraepithelial } \\
\text { leucocytes } \\
\downarrow \text { Distal intestine intraepithelial } \\
\text { leucocytes } \\
\uparrow \text { OTUs, and PD whole tree and } \\
\text { Chao1 diversity indexes } \\
\downarrow \text { Thermi phylum and Bacteroides, } \\
\text { Candidatus Cardinium, and } \\
\text { Leptospirillum genera }\end{array}$ & $\begin{array}{l}\text { Affect the immunity primarily through a } \\
\text { direct effect on host tissue but also } \\
\text { has an indirect effect mediated by } \\
\text { microbial changes }\end{array}$ & Ran, $\mathrm{Hu}(107)$ \\
\hline $\begin{array}{l}\text { Phytogenics } \\
\text { combination }\end{array}$ & Essential oils & 100 ppm & 9 weeks & $\begin{array}{l}25 \% \text { thymol and } 25 \% \text { carvacrol } \\
\text { (commercial additive) }\end{array}$ & $\begin{array}{l}\text { Gilthead seabream } \\
\text { (Sparus aurata) }\end{array}$ & $\downarrow F G R$ & $\begin{array}{l}\uparrow \text { Intestine mucosal foldings } \\
\uparrow \text { Intestine enterocytes } \\
\uparrow \text { Intestine goblet cells } \\
\downarrow \text { Expression of genes related to cell } \\
\text { differentiation and proliferation, } \\
\text { intestinal architecture and } \\
\text { permeability, immunosurveillance, } \\
\text { such as cytokines, in the intestine }\end{array}$ & $\begin{array}{l}\text { Induce an anti-inflammatory and anti- } \\
\text { proliferative transcriptomic profile with } \\
\text { probable improvement in the } \\
\text { absorptive capacity of the intestine }\end{array}$ & $\begin{array}{l}\text { Perez-Sanchez, } \\
\text { Benedito-Palos } \\
\text { (108) }\end{array}$ \\
\hline
\end{tabular}

SGR, Specific Growth Rate.

FCR, Feed Conversion Ratio.

FGR, Feed Gain Ratio.

OTU, Operational Taxonomic Unit.

*Indicate the putative plant species with high content of the referred bioactive compound. N/l, not identified or not assessed.

Studies reporting the application of plant extracts or related compounds as bath treatments or evaluating bactericidal or antiparasitic effects in vitro were excluded from the selection. The table omits systemic immunity-related results, digestive

enzymes or other complementary analysis performed within each study. Blends with other components besides the selected group of plants, terpenes or organosulfur compounds were excluded as well. 
mucus, few studies have tried to explain and characterize the immunomodulatory mechanisms underlying such responses neither which specific compounds might be exerting such effects.

Carvacrol, thymol, p-cymene and $\gamma$-terpinene are identified as the predominant bioactive compounds of most of the members of the Lamiaceae family considered in this review, which were mainly found in oregano and thyme. In addition, peppermint, rosemary and basil contain preponderant concentration of other bioactive compounds such menthol, eugenol and 1,8-cineole (Table 1). Interestingly, some studies have reported carvacrol and 1,8 -cineole presence in the fish skin mucus $(63,81)$. This phenomenon of bioactive compounds efflux through skin could be responsible for the immunomodulatory and antimicrobial effects observed in the fish skin mucus. However, most of the reviewed studies did not report the phytogenics composition neither the assessment of their translocation through mucus.

Some studies have also reported a protective effect through the reduction in gills' histopathological lesions induced by toxic element exposure or pathogenic challenges $(62,66,85)$. Contrarily to the studies describing the effects of phytogenics upon skin mucus secretion and their immunomodulatory potential, their impact upon the GIALT is very scarce, being mostly limited to histological observations. Similarly, studies on the impact of phytogenics upon the intestine are commonly focused on evaluating alterations in morphoanatomical parameters such as an increase in villus length, width and goblet cells count, which are usually associated to improvements in fish growth performance $(59,60,64,84,85)$. Some studies have also reported the modulation in the number of intestinal lymphocytes $(70,72)$. Other authors have described a positive impact upon the gastrointestinal activity of humoral immune markers, such lysozyme (86), the activity of antioxidant enzymes and oxidative markers $(67,106)$ or the down-regulation of the expression of pro-inflammatory genes, such $\operatorname{tnf} \alpha$ and $\operatorname{tnf} \beta$ (61). Besides, the beneficial impact of phytogenics administration upon the intestine microbiota composition was also suggested $(61,87)$. Nonetheless, analysis described were constantly incomplete in terms of mucosal immune response evaluation, since limited classical immune or oxidative markers were assessed in each of the above-mentioned studies. Similarly, microbiota studies were often restricted to a particular group of bacteria, such lactic bacteria, failing to properly characterize microbiota functionality and modulation by the experimental diets; thus, resulting in partial and biased conclusions when assessing the regulatory effects of functional feed additives on mucosal tissues.

In addition, some studies reported no effect of the administrated phytogenics upon mucosal parameters $(68,69,80,82,83)$. Such discrepancies among studies evaluating a particular plant extracts may be due to the diversity of the referred studies in terms of experimental design, fish species selected, plant origin, supplemented form and inclusion level of phytogenetics, among others. This miscellaneous of studies and the lack of protocols allowing appropriate additive and animal testing, highlights the urgent need to standardize the experimental designs and procedures in order to properly evaluate these compounds under in vivo conditions and acquire relevant data for their further development and general and safe use.

The effect of some single specific bioactive compounds related to aromatic plants of the Lamiaceae family, such thymol or carvacrol, upon mucosal tissues were also reported (Table 1). Although these studies have the advantage to associate a specific mucosal response to the administration of a specific compound, once again it is observed that most of them only reported the analysis of few immune and oxidative markers $(97,98,101,103)$, or a limited microbiological examination $(99,100)$. In fact, few studies were observed to apply complementary analysis, or achieved to successfully discuss the multifactorial impact exerted by such nutritional strategies upon mucosal tissues (107, 108).

Although the overall data suggest the therapeutic potential of phytogenics derived from Lamiaceae family of plants in aquafeeds, especially of their associated terpene phenolic compounds, unfortunately none of the studies has proposed accurate mechanisms that could be responsible for the broad effects of these metabolites described upon fish mucosal tissues. Despite the lack of reliable information for aquaculture relevant fish species, it is possible that the above-mentioned antimicrobial properties of these compounds, their free radicals' scavenging ability, along with their aptitude to activate TRP channels that modulate inflammatory processes may underlie the immunomodulatory properties and microbiota modulation described in different mucosal tissues.

\section{Effect of Dietary Organosulfur Compounds Upon Fish Mucosal Immunity}

The main constituents of extracts and essential oils from Allium sp., such as garlic (Allium sativum, Alliaceae) and onion (Allium cepa, Alliaceae), are sulfur-containing compounds. This group of bioactive substances comprises alliin, allicin and its derived bioactive compounds like ajoene, diallyl trisulfide (DATS), diallyl disulfide (DADS), diallyl sulfide (DAS) and allyl methyl disulfide, commonly termed as organosulfur compounds. These organosulfur compounds are the responsible for the recognized antioxidative, antimicrobial, antifungal and antiparasitic properties of garlic (126). Allicin (S-allyl-2-propenyl thiosulfinate) is usually the main biologically active component of garlic and related species; however, it is highly unstable under physiological conditions; thus, quickly being transformed into its organosulfur derivates, which also exhibit therapeutic properties (127-129).

Organosulfur compounds have been particularly studied for their antiparasitic activity. Among them, ajoene was described to interfere with parasite and host cell membrane protein and lipid trafficking, with irreversible detrimental consequences for the parasite (130). This is of special relevance since teleost mucosal tissues are known to have a high constitutive expression of Th2 markers that indicate a skewed immune response targeted against parasites (131). Regarding their bactericidal properties, the organosulfur compounds can penetrate the bacterial cell membranes, cause changes in the structure of thiol (-SH) containing enzymes and proteins, and lower the expression of important genes involved in the QS in bacteria, inhibiting the 
growth of both Gram-positive and Gram-negative bacteria (132). The higher the number of sulfur atoms present in the compounds, the more is its bactericidal activity (133). Therefore, the administration of organosulfur-containing phytogenics may induce important changes in the fish mucosal-associated microbiota with potential effects upon the mucosal immunity.

The detoxification and chemoprotective benefits from various organosulfur compounds have been associated to their ability to scavenge free radicals and selectively enhance or suppress the levels genes or proteins of several antioxidant enzymes, such as cytochrome P450 enzymes or glutathione S-transferase (GST) (134), exerting a direct effect upon immune cells (135). In this line, their anti-inflammatory activity upon immune and intestinal epithelial cells was associated to the inhibition of ROS production and the modulation of the NF- $k$ B and MAPK signaling pathways $(136,137)$. Some organosulfur compounds, such allyl sulphides, were also observed to increase the levels of anti-inflammatory $\mathrm{H}_{2} \mathrm{~S}$ in intestinal epithelial cells, promoting mucosal integrity, tissue repair and stimuli perception (138). In accordance, organosulfur compounds, such as DADS, are also donors of $\mathrm{H}_{2} \mathrm{~S}$, whose positive effects upon the intestinal health could be also produced through the modulation of the enteric microbiota (139). In addition, organosulfur compounds were observed to promote mucin expression in human airway epithelial cells, being suggested to improve the mucosal epithelial barrier function $(140,141)$.

Conversely, these organosulfur compounds have been also reported to stimulate inflammatory immune responses, promoting the release of pro-inflammatory cytokines, enhancing the proliferation of lymphocytes, macrophage phagocytosis and modulating the infiltration of immune cells (142). For instance, it was demonstrated that some allyl-containing organosulfur compounds directly activate $\mathrm{Ca}^{2+}$ flux in neutrophils augmenting their phagocytic function and consequent ROS production. In parallel, other compounds are able to inhibit spontaneous ROS production by neutrophils (143). This apparent antagonistic effect evidences the pleiotropic protective effects of garlic extracts and essential oils, being simultaneously capable of inducing immune responses and anti-inflammatory counteractions. Moreover, as previously suggested for the mode of action of terpene phenolic compounds, organosulfur compounds are also able to activate TRP channels, TRPA1 and TRPV1 channels in particular (144-146), suggesting the $\mathrm{Ca}^{2+}$ induced cellular immune activation (143).

Garlic has been for long studied and recognized for its benefits as growth- and flesh quality-promoting effects in cultured fish, as well as for its antibacterial and antiparasitic properties (51). However, there is scarce information regarding the activity of garlic-derived organosulfur bioactive compounds upon fish mucosal tissues. The synthesis of the results from several studies reporting the health promoting properties of phytogenics derived from Allium sp. are shown in Table $\mathbf{1}$. Similar to studies testing phytogenics from Lamiaceae family origin, the evaluation of the supplementation of phytogenics derived from Allium sp., also focuses on few immune markers in skin mucus $(88,93)$, histopathological observations or some inflammatory and oxidative markers in gills $(89,96)$ and intestine $(90,94-96,102)$, or incomplete microbiological examination that lacks in-depth the functional interpretation of their mode of action at cellular level $(87,90,92)$.

Overall, studies reporting the effect of the administration of phytogenics derived from Allium sp. upon fish mucosal tissue suggest the health-promoting potential of the organosulfur compounds that characterize this group of plants. However, there is currently no robust studies under a pharmacological point of view that intent to demystify the accurate mechanisms responsible for the effects described on fish mucosal tissues, whose lack of reliable information critically restrains their application as potential functional feed additives in aquafeeds. Similar to the terpene phenolic compounds, the organosulfur compounds have also recognized antipathogenic and antioxidant properties, in addition to their common ability to activate TRP channels that modulate inflammatory processes. Since in higher vertebrates dermal emission of organosulfur compounds were demonstrated after garlic ingestion (147). In this sense, the efflux of organosulfur compounds through the integument could be also playing a critical role in the recurrently reported effects of dietary garlic and other aromatic plants in fish mucus, as previously referred for carvacrol and 1,8-cineole.

\section{Effect of Combinations of Phytogenics Derived From Lamiaceae and Allium sp. Upon Fish Mucosal Immunity}

Some studies have reported the beneficial effects of the combination of Lamiaceae and Allium sp. phytogenics upon fish mucosal tissues (Table 1). For instance, in European seabass (Dicentrarchus labrax) a combination of garlic and essential oils from plants of the Lamiaceae family promoted skin mucus lysozyme activity and fish survival against $V$. anguillarum when exposed to a confinement stress (104). In greater amberjack (Seriola dumerili), the same additive induced an upregulation of a set of immune related genes in the skin in response to a monogenean parasite Neobenedenia girellae infection (16). In accordance, a blend of garlic essential oils, carvacrol and thymol was also reported to positively impact both gilthead seabream (Sparus aurata) skin mucus in terms of bacterial inhibition capacity against fish pathogens and decrease of stress markers, whereas the transcriptional analysis suggested the stimulation of the secretory pathway possibly associated to humoral immune molecules secretion into mucus and activation of phagocytic cells (14). The same blend was reported to regulate the transcription of genes related to immune response in gills, which was mediated by granulocytes, as well as sustaining both anti-inflammatory and antioxidative responses. In addition, the above-mentioned study revealed that the tested phytogenic compounds promoted the presence of sialic-acids containing glycoproteins in both epithelial and mucous cells, which globally resulted in a decrease in the intensity of gills' infestation by the monogenean ectoparasite Sparicotyle chrysophrii in gilthead seabream (15). Both, referred phytogenics combinations were observed to positively affect the gut health status of those fish species by improving the 
protective intestine mucus coverage post-challenge (13), regulating the intestine immune transcription (12) and modulating their intestinal microbiota $(12,105)$.

According to the above-described studies and the acknowledged properties of these phytogenics' bioactive compounds, we suggest that the mechanisms of cell activation that may be responsible for the mucosal immune-related responses are mediated by the activation of TRP cation channels in both immune and epithelial cells of mucosal tissues. The bioactive compounds may activate TRP channels leading to intracellular $\mathrm{Ca}^{2+}$ increase and the activation of the TAK1/MAPK/NF- $k$ B signaling pathways, modulating the expression of pro-and anti-inflammatory cytokines, and antioxidative enzymes such as cytochrome P450. In parallel, stimulation by pathogen-associated molecular patterns (PAMPs), who might be also modulated by the antimicrobial properties of these compounds, may facilitate the activation of TLR and TRP signaling pathways; thus, amplifying the mucosal immune responses. Moreover, the bioactive compounds are also suggested to passively diffuse across the cell membrane, scavenging ROS that contribute to the inflammatory pathways, and interacting with TRP channels of the endoplasmic reticulum, potentially stimulating the secretory pathway. The above-described mode of action of phytogenics derived from Lamiaceae family and Allium sp. at the level of the main mucosal lymphoid tissues in fish is depicted in Figure 1.

In addition, a summarized representation of the potential mucosal immune responses induced by the dietary administration of terpene and/or organosulfur based phytogenics and their effects against fish pathogenic organisms is suggested in Figure 2. In this representation, the holistic perspective of the compounds' effects upon the most studied mucosal-associated lymphoid tissues in fish so far - gill, gut, and skin - as targets for oral immunostimulation is highlighted through the stimulation of both humoral and cellular immunity, mucosal secretion, microbiota modulation and other potential physiological and metabolic responses.

\section{FUTURE PERSPECTIVES}

Feeding the projected world population by 2050 in a sustainable way is a great challenge, in which aquaculture is predicted to supply the majority of aquatic dietary protein. For that, the implementation of novel policies and production system approaches targeting effective health management and animal welfare are mandatory (1). Moreover, indiscriminate prophylactic use of antibiotics associated to intensive aquaculture practices can still be observed

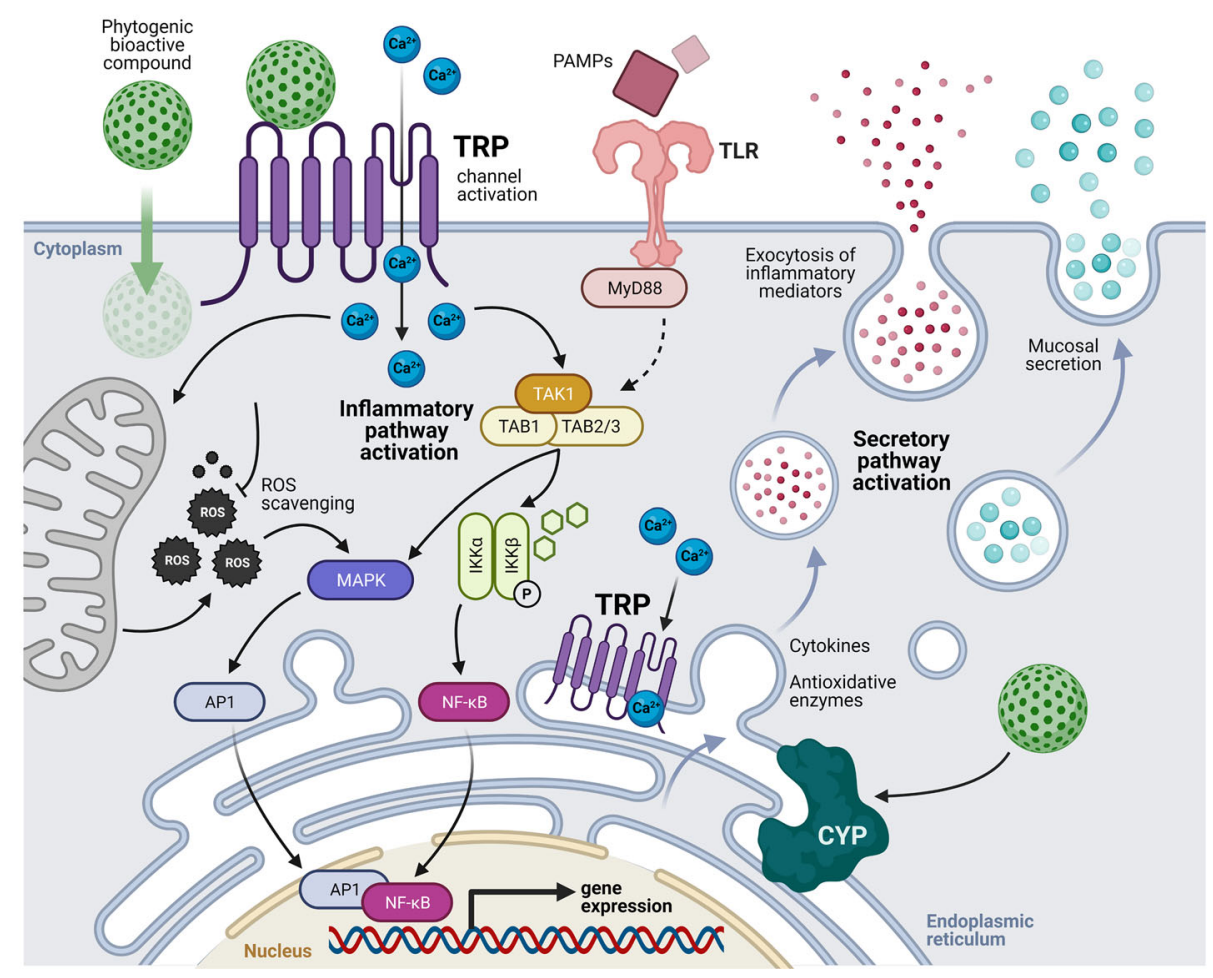

FIGURE 1 | Suggested mechanisms of cell activation by the transient receptor potential (TRP) cation channels mediated by phytogenics' bioactive compounds in mucosal-associated lymphoid tissues (MALTs). Bioactive compounds activate TRP channels leading to intracellular Ca ${ }^{2+}$ increase and non-canonical activation of the TAK complex. In parallel, stimulation by pathogen-associated molecular patterns (PAMPS) may facilitate the activation of TLR and TRP signaling pathways. Modified from Galindo-Villegas, et al. (124). TLR, toll-like receptors; MyD88, myeloid differentiation primary response 88; TAK, transforming growth factor beta (TGF $\beta$ ) activated kinase; TAB, TGF $\beta$ activated kinase binding protein; ROS, reactive oxygen species; NF-kB, nuclear factor kappa-B; IKK, inhibitor of NF-kB kinase; MAPK, mitogenactivated protein kinase; AP1, activator protein 1; CYP, cytochromes P450; P, phosphorylation. 


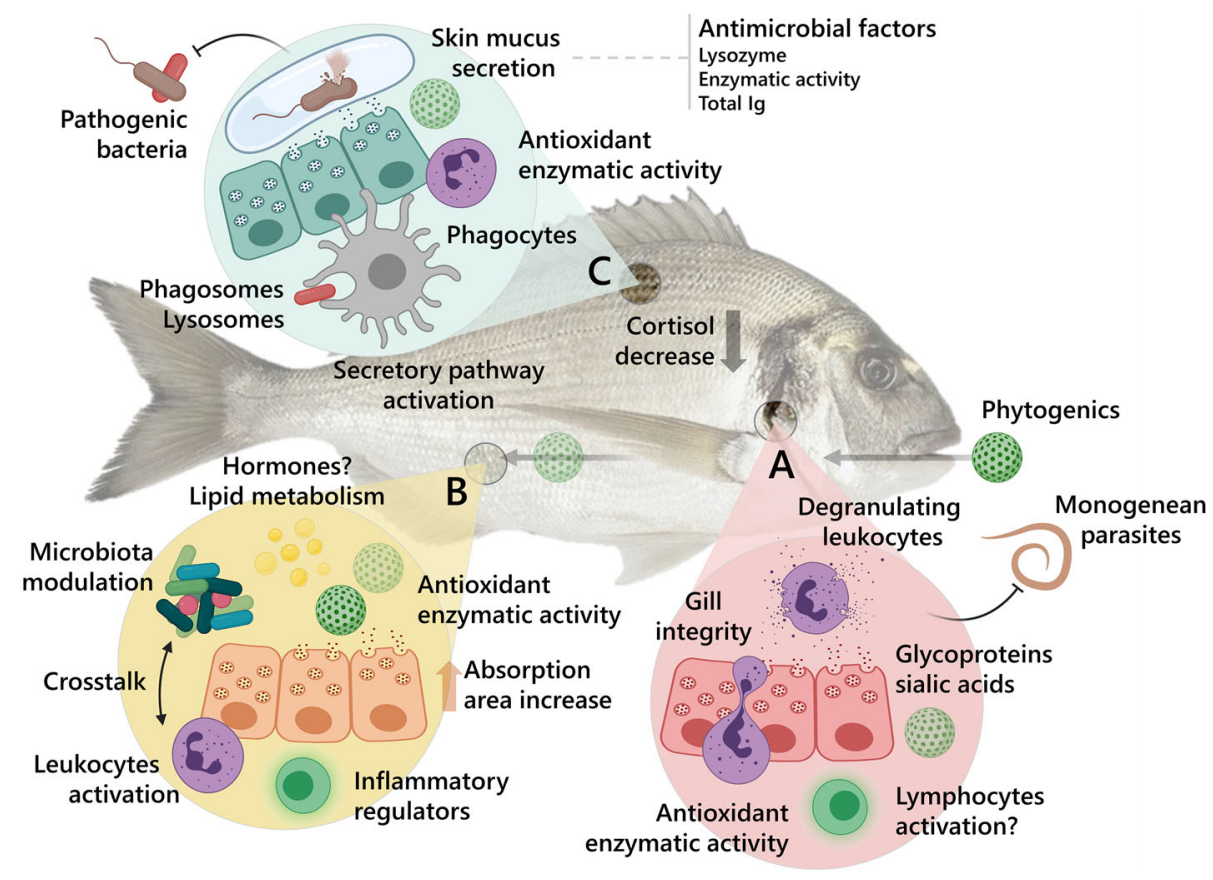

FIGURE 2 | Summary of the proposed mode of response induced by phytogenic bioactive compounds in fish mucosal tissues. The effects against representative types of common pathogens on the most studied mucosal-associated lymphoid tissues in fish so far are represented in the figure. (A) Gills. (B) Gut. (C) Skin. Gilthead seabream (S. aurata) was used in the figure as a representative aquaculture-relevant fish.

among some of the major aquaculture producing countries, as it has been recently reviewed $(148,149)$. However, in 2022, several countries, including the EU will prohibit all forms of routine antibiotic use in farming, including preventative group treatments which highlights the necessity for the development of more sustainable alternative treatments (150). Under this context, the market for sustainable products and feed additives is increasingly growing and the number of studies on the use of a wide variety phytogenics as sustainable tools to be implemented in aquaculture production has increased dramatically in the last decade (5). The global market of phytogenic feed additives including major tier I and II suppliers was estimated on 753M USD in 2020 and it is projected to reach 1,098M USD by 2025 (151).

Although limitations in testing and reproducing studies using dietary immunostimulants have been pointed out since long ago (152-155), the current knowledge on the pathways and mechanisms followed by these compounds at the cellular level is still neglected. A large selection of experimental designs, fish species, phytogenics tested and diet composition fails in the association of selected bioactive compounds to specific effects. Moreover, it is important to consider the difficulties to carry out comparison among the available studies because of the different assays, testing methods, different extraction procedures of plant essential oils or extracts, and the intrinsic variation in chemical phytoconstituents in plants due to different agroclimatic conditions, harvesting season and plant phenotype. This essential oils or extracts consist of a variable mixture of different bioactive molecules that area generally not characterized, and are administrated through variable periods of time, dietary doses and forms in different fish species that are generally randomly selected. In addition, a considerable number of these studies provide little or partial information regarding the effect of a given immunostimulant, since their definitive efficiency assessment rely on the evaluation of basic biochemical parameters that are to some extent obsolete if compared against the actual state-of-the-art. Based on the former idea, diverse omics tools available play a fundamental role for proper understanding and characterization of their mode of action in mucosal tissues at cellular level. Together, these factors question the reproducibility and safety of a large number of studies available and limits the use of several of those proposed substances in commercial functional feeds.

In this regard, we propose that the study of purified bioactive compounds may represent a viable solution to circumvent variability, and the biological mode of action of isolated compounds should be primarily assessed in vitro under variated settings, before moving forward to in vivo trials. However, it is important to consider that the biological activities of essential oils or extracts cannot be attributed to a single compound or to a unique specific mechanism, since their multi-component properties exert greater biological activity when compared to the major components alone, whose function is probably regulated by the synergy with limiting compounds (8). In this light, essential oils and extracts from different plants have been explored for their potential as resistance modifying agents (156). While their chemical complexity may represent a clear advantage in terms of reducing the risk of inducing bacterial adaptation and resistance to single compounds, or even promoting a wider antibacterial activity, the use of blends of 
phytogenics makes difficult to proper characterize their mode of action. Therefore, when developing such additives, the formulation of combined purified compounds through the correct and soundly in vitro functional characterization to obtain potential synergies is recommended. Moreover, long-term studies assessing whether the bioactive compounds, single or combined, induce bacterial tolerance, transmissible adapted resistance or any other change on a large scale should be implemented and the effects on both beneficial and pathogenic bacteria determined through in vitro, in silico and finally in vivo approaches $(103,157)$.

While several phytogenics have been proved remarkably efficient in promoting mucosal fitness (9), little efforts have been made to elucidate the underlying pharmacokinetics and immunostimulatory mechanisms of tested compounds upon the MALTs, with few in vitro studies published to date. It should also be highlighted that occasionally in vitro studies do not accurately translate into predictable responses in vivo (83); thus, both in vitro and in vivo studies should be performed whenever possible. This lack of complementary information supports the demand for additional profound research on the fate and length in which particular phytogenic compounds act, which is crucial for further developing functional additives and their application in an industrial context. Although the specific mechanisms behind the observed fish mucosal physiological responses are still poorly described, it is possible that cellular pathways involving the activation of TRP receptors by the bioactive compounds might be responsible for the reported mucosal immune responses. Besides, this response might be potentiated by the PAMPinduced activation of the TLR cell-signaling cascade, as synthetized in Figure 1, which would explain the fish improved ability to cope with pathogenic challenges. Thus, it is advisable in nutritional dose-response evaluating phytogenics to evaluate changes in expression in TRP receptors as well as gene markers of the TAK1/MAPK/NF- $k$ B signaling pathways in order to provide insight into their mode of action at mucosal level.

Another limitation that should be taken into account when testing phytogenics is that most plant-derived bioactive compounds are either volatile and/or susceptible to rapid degradation in the stomach where acid digestion takes place, with consequent low availability at the intestinal level or uncontrolled changes in the dose of administration. Hence, to overcome this limitation and minimize potential losses, controlled releasing techniques, such as encapsulation or other coating technologies, can be used to improve the proper delivery of phytogenics. This technology allows a prolonged absorption and local availability of the bioactive compounds along the gastrointestinal tract, ultimately increasing their beneficial impact upon the host $(158,159)$. Moreover, encapsulation protects phytogenics from environmental degradation, such as from light, temperature and/or $\mathrm{pH}$ variations, and eventually playing an important role in their palatability, masking the potential pungency associated to some compounds that otherwise can affect feed intake (158). It is important to highlight that most of the studies considered in this review did not take into consideration those aspects, administrating phytogenics as powder forms, hydroethanolic extracts or dissolved solutions without proper assessment of their potential biodegradation during feed storage or along the gastrointestinal tract. The overall limitations identified in most of the currently available studies assessing fish immunity leads to the stigmatization of phytogenics application, in which compounds with high pharmacological value are labeled under the "medicinal plants" or "herbalism" pseudoscience stigma, with disbelieving scientific evidence. This represents a major restriction for the development of effective phytogenics at commercial scale.

\section{CONCLUSIONS}

Overall, it is fundamental that the efforts made in the research for sustainable prophylactic tools to boost host's immune condition, stress resistance and pathogenesis prevention will culminate on reliable administration strategies for the aquaculture sector. Among the most studied group of natural bioactive compounds, both terpenes and organosulfur compounds have been suggested to display antimicrobial, antioxidant, antiinflammatory and immunomodulating activities, with the potential of improving fish mucosal barrier function and integrity. Although they comprise a promising group of phytogenics for aquafeeds, an urgent update in the academical approach and experimental methodologies are needed to elucidate their pharmacokinetics and mode of action in depth. Therefore, in the present review we propose important molecular signaling pathways and hypothesize their involvement on the dietary immunomodulation in fish by the selected phytogenics.

\section{AUTHOR CONTRIBUTIONS}

JF and JG-V data analysis and visualization. JF wrote the draft. All authors contributed to the article and approved the submitted version.

\section{ACKNOWLEDGMENTS}

Authors thank the support of the projects: (1) Nutritional strategies for the improvement of productive performance: the use of functional feeds and health diets in aquaculture (DIETAplus), funded by JACUMAR (Ministry of Agriculture, Fisheries and Environment of Spain, MAPAMA) and FEMP (EU); (2) LARVAplus network Strategies for the development and improvement of fish larvae production in Ibero-America (117RT0521) funded by the Ibero-American Program of Science and Technology for Development (CYTED, Spain); (3) FR-L thanks the support of Fondecyt regular grant (project number 1211841; Agencia Nacional de Investigación y Desarrollo [ANID]; Government of Chile); (4) JF has been subsidized by the Industrial PhD program of Generalitat de Catalunya and TECNOVITFARMFAES S.L. (Nb. 2017 DI 017). The funder was not involved in the study design, collection, analysis, interpretation of data, the writing of this article or the decision to submit it for publication. (5) European Research Council (ERC) under the European Union's Horizon 2020 research and innovation programme (grant 683210). Nord University Access Fund covers the OA publication cost. 


\section{REFERENCES}

1. Costello C, Cao L, Gelcich S, Cisneros-Mata >M.Á., Free CM, Froehlich HE, et al. The Future of Food From The Sea. Nature (2020) 588(7836):95-100. doi: $10.1038 / s 41586-020-2616-y$

2. Waagbø R, Remø SC. 7 - Functional Diets in Fish Health Management. In: FSB Kibenge and MD Powell, editors. Aquaculture Health Management. Cambridge, Massachusetts: Academic Press (2020). p. 187-234. p. p. doi: 10.1016/B978-0-12-813359-0.00007-5

3. Christaki E, Giannenas I, Bonos E, Florou-Paneri P. Chapter 2 - Innovative Uses of Aromatic Plants as Natural Supplements in Nutrition. In: P FlorouPaneri, E Christaki and I Giannenas, editors. Feed Additives. Cambridge, Massachusetts: Academic Press (2020). p. 19-34. p. p. doi: 10.1016/B978-012-814700-9.00002-9

4. Suphoronski SA, Chideroli RT, Facimoto CT, Mainardi RM, Souza FP, Lopera-Barrero NM, et al. Effects of a Phytogenic, Alone and Associated With Potassium Diformate, on Tilapia Growth, Immunity, Gut Microbiome and Resistance Against Francisellosis. Sci Rep (2019) 9(1):6045. doi: 10.1038/s41598-019-42480-8

5. Reverter M, Tapissier-Bontemps N, Sarter S, Sasal P, Caruso D. Moving towards More Sustainable Aquaculture Practices: A Meta-Analysis on the Potential of Plant-Enriched Diets to Improve Fish Growth, Immunity and Disease Resistance. Rev Aquaculture (2021) 13(1):537-55. doi: 10.1111/ raq. 12485

6. Franz CM, Baser KHC, Hahn-Ramssl I. Chapter 3 - Herbs and Aromatic Plants as Feed Additives: Aspects of Composition, Safety, and Registration Rules. In: P Florou-Paneri, E Christaki and I Giannenas, editors. Feed Additives. Cambridge, Massachusetts: Academic Press (2020). p. 35-56. doi: 10.1016/B978-0-12-814700-9.00003-0

7. Napoli E, Siracusa L, Ruberto G. New Tricks for Old Guys: Recent Developments in the Chemistry, Biochemistry, Applications and Exploitation of Selected Species From the Lamiaceae Family. Chem Biodiversity (2020) 17(3):e1900677. doi: 10.1002/cbdv.201900677

8. Zheng X, Feyaerts AF, Van Dijck P, Bossier P. Inhibitory Activity of Essential Oils Against Vibrio campbellii and Vibrio parahaemolyticus. Microorganisms (2020) 8(12):1946. doi: 10.3390/microorganisms8121946

9. Hoseinifar SH, Sun Y-Z, Zhou Z, Van Doan H, Davies SJ, Harikrishnan R. Boosting Immune Function and Disease Bio-Control Through Environment-Friendly and Sustainable Approaches in Finfish Aquaculture: Herbal Therapy Scenarios. Rev Fisheries Sci Aquaculture (2020) 28(3):303-21. doi: 10.1080/23308249.2020.1731420

10. FAO. The State of World Fisheries and Aquaculture (sofia). In: . Sustainability in Action. Rome: FAO (2020). doi: 10.4060/ca9229en

11. Yu Y, Wang Q, Huang Z, Ding L, Xu Z. Immunoglobulins, Mucosal Immunity and Vaccination in Teleost Fish. Front Immunol (2020) 11:114. doi: 10.3389 /fimmu.2020.567941

12. Firmino JP, Vallejos-Vidal E, Balebona MC, Ramayo-Caldas Y, Cerezo IM, Salomón R, et al. Diet, Immunity, and Microbiota Interactions: An Integrative Analysis of the Intestine Transcriptional Response and Microbiota Modulation in Gilthead Seabream (Sparus aurata) Fed an Essential Oils-Based Functional Diet. Front Immunol (2021) 12:625297 (356). doi: 10.3389/fimmu.2021.625297

13. Torrecillas S, Terova G, Makol A, Serradell A, Valdenegro V, Gini E, et al. Dietary Phytogenics and Galactomannan Oligosaccharides in Low Fish Meal and Fish Oil-Based Diets for European Sea Bass (Dicentrarchus labrax) Juveniles: Effects on Gut Health and Implications on in vivo Gut Bacterial Translocation. PloS One (2019) 14(9):1-31. doi: 10.1371/journal.pone.0222063

14. Firmino JP, Fernández-Alacid L, Vallejos-Vidal E, Salomón R, Sanahuja I, Tort L, et al. Carvacrol, Thymol, and Garlic Essential Oil Promote Skin Innate Immunity in Gilthead Seabream (Sparus aurata) Through the Multifactorial Modulation of the Secretory Pathway and Enhancement of Mucus Protective Capacity. Front Immunol (2021) 12:633621(559). doi: 10.3389/fimmu.2021.633621

15. Firmino JP, Vallejos-Vidal E, Sarasquete C, Ortiz-Delgado JB, Balasch JC, Tort L, et al. Unveiling the Effect of Dietary Essential Oils Supplementation in Sparus aurata Gills and Its Efficiency Against the Infestation by Sparicotyle Chrysophrii. Sci Rep (2020) 10(1):1-23. doi: 10.1038/s41598020-74625-5
16. Fernández-Montero Á., Torrecillas $S$, Acosta F, Kalinowski T, Bravo J, Sweetman J, et al. Improving Greater Amberjack (Seriola dumerili) Defenses Against Monogenean Parasite Neobenedenia Girellae Infection Through Functional Dietary Additives. Aquaculture (2021) 534:736317. doi: 10.1016/j.aquaculture.2020.736317

17. Egerton S, Culloty S, Whooley J, Stanton C, Ross RP. The Gut Microbiota of Marine Fish. Front Microbiol (2018) 9:1-17. doi: 10.3389/fmicb. 2018.00873

18. Butt RL, Volkoff H. Gut Microbiota and Energy Homeostasis in Fish. Front Endocrinol (2019) 10:1-12. doi: 10.3389/fendo.2019.00009

19. Gomez D, Sunyer JO, Salinas I. The Mucosal Immune System of Fish: The Evolution of Tolerating Commensals While Fighting Pathogens. Fish Shellfish Immunol (2013) 35(6):1729-39. doi: 10.1016/j.fsi.2013.09.032

20. Randall TD, Mebius RE. The Development and Function of Mucosal Lymphoid Tissues: A Balancing Act With Micro-Organisms. Mucosal Immunol (2014) 7(3):455-66. doi: 10.1038/mi.2014.11

21. Galindo-Villegas J, García-Moreno D, de Oliveira S, Meseguer J, Mulero V. Regulation of Immunity and Disease Resistance by Commensal Microbes and Chromatin Modifications During Zebrafish Development. Proc Natl Acad Sci (2012) 109(39):E2605-14. doi: 10.1073/pnas.1209920109

22. Yu Y-Y, Kong W-G, Xu H-Y, Huang Z-Y, Zhang X-T, Ding L-G, et al. Convergent Evolution of Mucosal Immune Responses at the Buccal Cavity of Teleost Fish. iScience (2019) 19:821-35. doi: 10.1016/j.isci.2019.08.034

23. Salinas I, Fernández-Montero Á., Ding Y, Sunyer JO. Mucosal Immunoglobulins of Teleost Fish: A Decade of Advances. Dev Comp Immunol (2021) 121:104079. doi: 10.1016/j.dci.2021.104079

24. Sahoo BR. Structure of Fish Toll-Like Receptors (tlr) and Nod-Like Receptors (nlr). Int J Biol Macromolecules (2020) 161:1602-17. doi: 10.1016/j.ijbiomac.2020.07.293

25. Chen SN, Zou PF, Nie P. Retinoic Acid-Inducible Gene i (rig-i)-Like Receptors (rlrs) in Fish: Current Knowledge and Future Perspectives. Immunology (2017) 151(1):16-25. doi: 10.1111/imm.12714

26. Yamaguchi T, Dijkstra JM. Major Histocompatibility Complex (mhc) Genes and Disease Resistance in fish. Cells (2019) 8(4):378. doi: 10.3390/ cells 8040378

27. Wilson $\mathrm{AB}$. Mhc and Adaptive Immunity in Teleost Fishes. Immunogenetics (2017) 69(8):521-8. doi: 10.1007/s00251-017-1009-3

28. Castro R, Bernard D, Lefranc MP, Six A, Benmansour A, Boudinot P. T Cell Diversity and tcr Repertoires in Teleost Fish. Fish Shellfish Immunol (2011) 31(5):644-54. doi: 10.1016/j.fsi.2010.08.016

29. Rombout JHWM, Yang G, Kiron V. Adaptive Immune Responses at Mucosal Surfaces Of Teleost Fish. Fish Shellish Immunol (2014) 40 (2):634-43. doi: 10.1016/j.fsi.2014.08.020

30. Salinas I. The Mucosal Immune System of Teleost Fish. Biology (2015) 4 (3):525-39. doi: 10.3390/biology4030525

31. Galindo-Villegas J, Mulero I, García-Alcazar A, Muñoz I, Peñalver-Mellado M, Streitenberger S, et al. Recombinant tnf $\alpha$ as Oral Vaccine Adjuvant Protects European Sea Bass Against Vibriosis: Insights Into the Role of the ccl25/ccr9 Axis. Fish Shellfish Immunol (2013) 35(4):1260-71. doi: 10.1016/ j.fsi.2013.07.046

32. Bjørgen H, Koppang EO. Anatomy of Teleost Fish Immune Structures and Organs. Immunogenetics (2021) 73(1):53-63. doi: 10.1007/s00251-02001196-0

33. Li J, Barreda DR, Zhang Y-A, Boshra H, Gelman AE, LaPatra S, et al. B Lymphocytes From Early Vertebrates Have Potent Phagocytic and Microbicidal Abilities. Nat Immunol (2006) 7(10):1116-24. doi: 10.1038/ nil389

34. Wu L, Qin Z, Liu H, Lin L, Ye J, Li J. Recent Advances on Phagocytic B Cells in Teleost Fish. Front Immunol (2020) 11:1-9. doi: 10.3389/fimmu. 2020.00824

35. Perdiguero P, Martín-Martín A, Benedicenti O, Díaz-Rosales P, Morel E, Muñoz-Atienza E, et al. Teleost IgD+IgM- B Cells Mount Clonally Expanded and Mildly Mutated Intestinal IgD Responses in the Absence of Lymphoid Follicles. Cell Rep (2019) 29(13):4223-4235.e5. doi: 10.1016/ j.celrep.2019.11.101

36. Zhang Y-A, Salinas I, Li J, Parra D, Bjork S, Xu Z, et al. IgT, a Primitive Immunoglobulin Class Specialized in Mucosal Immunity. Nat Immunol (2010) 11(9):827-35. doi: 10.1038/ni.1913 
37. Piazzon MC, Galindo-Villegas J, Pereiro P, Estensoro I, Calduch-Giner JA, Gómez-Casado E, et al. Differential Modulation of IgT and IgM Upon Parasitic, Bacterial, Viral, and Dietary Challenges in a Perciform Fish. Front Immunol (2016) 7:1-16. doi: 10.3389/fimmu.2016.00637

38. Cabillon NAR, Lazado CC. Mucosal Barrier Functions of Fish Under Changing Environmental Conditions. Fishes (2019) 4(1):2. doi: 10.3390/ fishes 4010002

39. Montalban-Arques A, De Schryver P, Bossier P, Gorkiewicz G, Mulero V, Gatlin DM, et al. Selective Manipulation of the Gut Microbiota Improves Immune Status in Vertebrates. Front Immunol (2015) 6:1-14. doi: 10.3389/ fimmu.2015.00512

40. Peterson TS. 3 - Overview of Mucosal Structure and Function in Teleost Fishes. In: BH Beck and E Peatman, editors. Mucosal Health in Aquaculture. San Diego: Academic Press (2015). p. 55-65. doi: 10.1016/B978-0-12417186-2.00003-0

41. Reverter M, Tapissier-Bontemps N, Lecchini D, Banaigs B, Sasal P. Biological and Ecological Roles of External Fish Mucus: A revIew. Fishes (2018) 3(4):41. doi: 10.3390/fishes3040041

42. Kelly C, Salinas I. Under Pressure: Interactions Between Commensal Microbiota and the Teleost Immune System. Front Immunol (2017) 8:1-9. doi: 10.3389/fimmu.2017.00559

43. Boutin S, Bernatchez L, Audet C, Derôme N. Network Analysis Highlights Complex Interactions Between Pathogen, Host and Commensal Microbiota. PloS One (2013) 8(12):e84772. doi: 10.1371/journal.pone.0084772

44. Ibarz A, Ordóñez-Grande B, Sanahuja I, Sánchez-Nuño S, Fernández-Borràs J, Blasco J, et al. Using Stable Isotope Analysis to Study Skin Mucus Exudation and Renewal in Fish. J Exp Biol (2019) 222(8):jeb.195925. doi: $10.1242 /$ jeb. 195925

45. Reyes-López FE, Ibarz A, Ordóñez-Grande B, Vallejos-Vidal E, Andree KB, Balasch JC, et al. Skin Multi-Omics-Based Interactome Analysis: Integrating the Tissue and Mucus Exuded Layer for a Comprehensive Understanding of the Teleost Mucosa Functionality as Model of Study. Front Immunol (2021) 11:1-20. doi: 10.3389/fimmu.2020.613824

46. Wink M. Plant Secondary Metabolites Modulate Insect Behavior-Steps Toward Addiction? Front Physiol (2018) 9:1-9. doi: 10.3389/ fphys.2018.00364

47. Figueiredo AC, Barroso JG, Pedro LG, Scheffer JJC. Factors Affecting Secondary Metabolite Production In plants: Volatile Components and Essential Oils. Flavour Fragrance J (2008) 23(4):213-26. doi: 10.1002/ffj.1875

48. Elumalai P, Kurian A, Lakshmi S, Faggio C, Esteban MA, Ringø E. Herbal Immunomodulators in Aquaculture. Rev Fisheries Sci Aquaculture (2020) 29 (1):33-57. doi: 10.1080/23308249.2020.1779651

49. Christaki E, Bonos E, Giannenas I, Florou-Paneri P. Aromatic Plants as a Source of Bioactive Compounds. Agriculture (2012) 2(3):228-43. doi: 10.3390/agriculture2030228

50. Grigoriadou K, Krigas N, Lazari D, Maloupa E. Chapter 4 - Sustainable Use of Mediterranean Medicinal-Aromatic Plants. In: P Florou-Paneri, E Christaki and I Giannenas, editors. Feed Additives. Cambridge, Massachusetts: Academic Press (2020). p. 57-74. doi: 10.1016/B978-0-12814700-9.00004-2

51. Lee J-Y, Gao Y. Review of the Application of Garlic, Allium sativum, in aquaculture. J World Aquaculture Society (2012) 43(4):447-58. doi: 10.1111/ j.1749-7345.2012.00581.x

52. Van Hai N. The use of Medicinal Plants as Immunostimulants in Aquaculture: A Review. Aquaculture (2015) 446:88-96. doi: 10.1016/ j.aquaculture.2015.03.014

53. de Freitas Souza C, Baldissera MD, Baldisserotto B, Heinzmann BM, Martos-Sitcha JA, Mancera JM. Essential Oils as Stress-Reducing Agents for Fish Aquaculture: A Review. Front Physiol (2019) 10:1-17. doi: 10.3389/ fphys.2019.00785

54. Aydın B, Barbas LAL. Sedative and Anesthetic Properties of Essential Oils and Their Active Compounds in Fish: A Review. Aquaculture (2020) 520:734999. doi: 10.1016/j.aquaculture.2020.734999

55. Alagawany M, Farag MR, Salah AS, Mahmoud MA. The Role of Oregano Herb and Its Derivatives as Immunomodulators in fiSh. Rev Aquaculture (2020) 12(4):2481-92. doi: 10.1111/raq.12453

56. Rashidian G, Boldaji JT, Rainis S, Prokić MD, Faggio C. Oregano (Origanum vulgare) Extract Enhances Zebrafish (Danio rerio) Growth Performance,
Serum and Mucus Innate Immune Responses and Resistance Against Aeromonas hydrophila Challenge. Animals (2021) 11(2):299. doi: 10.3390/ ani11020299

57. Beltrán JMG, Gonzalez Silvera D, Espinosa Ruiz C, Campo V, Chupani L, Faggio C, et al. Effects of Dietary Origanum vulgare on Gilthead Seabream (Sparus aurata 1.) Immune and Antioxidant Status. Fish Shellfish Immunol (2020) 99:452-61. doi: 10.1016/j.fsi.2020.02.040

58. Mohammadi G, Rafiee G, El Basuini MF, Van Doan H, Ahmed HA, Dawood $\mathrm{MAO}$, et al. Oregano (Origanum vulgare), St John's-wort (Hypericum perforatum), and Lemon Balm (Melissa officinalis) Extracts Improved the Growth Rate, Antioxidative, and Immunological Responses in Nile Tilapia (Oreochromis niloticus) Infected with Aeromonas hydrophila. Aquaculture Rep (2020) 18:1-9. doi: 10.1016/j.aqrep.2020.100445

59. Abdel-Latif HMR, Abdel-Tawwab M, Khafaga AF, Dawood MAO. Dietary Oregano Essential Oil Improved the Growth Performance via Enhancing the Intestinal Morphometry and Hepato-Renal Functions of Common Carp (Cyprinus carpio L.) fingerlings. Aquaculture (2020) 526:10. doi: 10.1016/ j.aquaculture.2020.735432

60. Heluy GM, Ramos LRV, Pedrosa VF, Sarturi C, Figueiredo PGP, Vidal LGP, et al. Oregano (Origanum vulgare) Essential Oil as an Additive in Diets for Nile Tilapia (Oreochromis niloticus) Fingerlings Reared in Salinized Water. Aquaculture Res (2020) 51(8):3237-43. doi: 10.1111/are.14658

61. Zhang R, Wang XW, Liu LL, Cao YC, Zhu H. Dietary Oregano Essential Oil Improved the Immune Response, Activity of Digestive Enzymes, and Intestinal Microbiota of the Koi Carp, Cyprinus carpio. Aquaculture (2020) 518:734781. doi: 10.1016/j.aquaculture.2019.734781

62. Khafaga AF, Naiel MAE, Dawood MAO, Abdel-Latif HMR. Dietary Origanum vulgare Essential Oil Attenuates Cypermethrin-Induced Biochemical Changes, Oxidative Stress, Histopathological Alterations, Apoptosis, and Reduces DNA Damage in Common Carp (Cyprinus carpio). Aquat Toxicol (2020) 228:1-16. doi: 10.1016/j.aquatox.2020.105624

63. Mizuno S, Urawa S, Miyamoto M, Hatakeyama M, Sasaki Y, Koide N, et al. Effects of Dietary Supplementation With Oregano Essential Oil on Prevention of the Ectoparasitic Protozoans Ichthyobodo salmonis and Trichodina truttae in Juvenile Chum Salmon Oncorhynchus keta. J Fish Biol (2018) 93(3):528-39. doi: 10.1111/jfb.13681

64. Ferreira PMF, Caldas DW, Salaro AL, Sartori SSR, Oliveira JM, Cardoso AJS, et al. Intestinal and Liver Morphometry of the Yellow Tail Tetra (Astyanax altiparanae) Fed With Oregano Oil. Anais Da Academia Bras Ciencias (2016) 88(2):911-22. doi: 10.1590/0001-3765201620150202

65. Yousefi M, Ghafarifarsani H, Hoseinifar SH, Rashidian G, Van Doan H. Effects of Dietary Marjoram, Origanum majorana Extract on Growth Performance, Hematological, Antioxidant, Humoral and Mucosal Immune Responses, and Resistance of Common Carp, Cyprinus carpio Against Aeromonas hydrophila. Fish Shellfish Immunol (2021) 108:127-33. doi: 10.1016/j.fsi.2020.11.019

66. El Euony OI, Elblehi SS, Abdel-Latif HM, Abdel-Daim MM, El-Sayed YS. Modulatory Role of Dietary Thymus vulgaris Essential Oil and Bacillus subtilis Against Thiamethoxam-Induced Hepatorenal Damage, Oxidative Stress, and Immunotoxicity in African Catfish (Clarias garipenus). Environ Sci Pollution Res (2020) 27(18):23108-28. doi: 10.1007/s11356-020-08588-5

67. Hoseini SM, Yousefi M. Beneficial Effects of Thyme (Thymus vulgaris) Extract on Oxytetracycline-Induced Stress Response, Immunosuppression, Oxidative Stress and Enzymatic Changes in Rainbow Trout (Oncorhynchus mykiss). Aquaculture Nutr (2019) 25(2):298-309. doi: 10.1111/anu.12853

68. Valladão GMR, Gallani SU, Kotzent S, Assane IM, Pilarski F. Effects of Dietary Thyme Essential Oil on Hemato-Immunological Indices, Intestinal Morphology, and Microbiota of Nile Tilapia. Aquaculture Int (2019) 27 (2):399-411. doi: 10.1007/s10499-018-0332-5

69. Navarrete P, Toledo I, Mardones P, Opazo R, Espejo R, Romero J. Effect of Thymus vulgaris Essential Oil on Intestinal Bacterial Microbiota of Rainbow Trout, Oncorhynchus mykiss (Walbaum) and Bacterial Isolates. Aquaculture Res (2010) 41(10):e667-78. doi: 10.1111/j.1365-2109.2010.02590.x

70. Hernandez A, Garcia Garcia B, Caballero MJ, Dolores Hernandez M. The Inclusion of Thyme Essential Oil in the Feed of Gilthead Seabream (Sparus aurata) Promotes Changes in the Frequency of Lymphocyte Aggregates in Gut-Associated Lymphoid Tissue. Aquaculture Res (2016) 47(10):3341-5. doi: 10.1111 /are.12758 
71. Paknejad H, Hosseini Shekarabi SP, Shamsaie Mehrgan M, Hajimoradloo A, Khorshidi Z, Rastegari S. Dietary Peppermint (Mentha piperita) Powder Affects Growth Performance, Hematological Indices, Skin Mucosal Immune Parameters, and Expression of Growth and Stress-Related Genes in Caspian Roach (Rutilus caspicus). Fish Physiol Biochem (2020) 46(5):1883-95. doi: 10.1007/s10695-020-00839-z

72. Valladão GMR, Gallani SU, Pala G, Jesus RB, Kotzent S, Costa JC, et al. Practical Diets With Essential Oils of Plants Activate the Complement System and Alter The Intestinal Morphology of Nile Tilapia. Aquaculture Res (2017) 48(11):5640-9. doi: 10.1111/are.13386

73. Adel M, Pourgholam R, Zorriehzahra J, Ghiasi M. Hemato - Immunological and Biochemical Parameters, Skin Antibacterial Activity, and Survival in Rainbow Trout (Oncorhynchus mykiss) Following the Diet Supplemented With Mentha piperita Against Yersinia ruckeri. Fish Shellfish Immunol (2016) 55:267-73. doi: 10.1016/j.fsi.2016.05.040

74. Adel M, Amiri AA, Zorriehzahra J, Nematolahi A, Esteban MA. Effects of Dietary Peppermint (Mentha piperita) on Growth Performance, Chemical Body Composition and Hematological and Immune Parameters of fry Caspian White Fish (Rutilus frisii kutum). Fish Shellfish Immunol (2015) 45(2):841-7. doi: 10.1016/j.fsi.2015.06.010

75. Adel M, Safari R, Pourgholam R, Zorriehzahra J, Angeles Esteban M. Dietary Peppermint (Mentha piperita) Extracts Promote Growth Performance and Increase the Main Humoral Immune Parameters (both at Mucosal and Systemic Level) of Caspian Brown Trout (Salmo trutta caspius Kessler, 1877). Fish Shellfish Immunol (2015) 47(1):623-9. doi: 10.1016/ j.fsi.2015.10.005

76. Gholamhosseini A, Adel M, Dawood MAO, Banaee M. The Potential Benefits Ofmentha Longifoliaon Growth Performance and Innate Immunity Parameters in Caspian Kutum (Rutilus frisii kutum). Aquaculture Res (2020) 51(12):5212-27. doi: 10.1111/are.14860

77. Heydari M, Firouzbakhsh F, Paknejad H. Effects of Mentha longifolia extract on some blood and immune parameters, and disease resistance against yersiniosis in rainbow trout. Aquaculture (2020) 515:1-8. doi: 10.1016/ j.aquaculture.2019.734586

78. Kurian A, Van Doan H, Tapingkae W, Elumalai P. Modulation of Mucosal Parameters, Innate Immunity, Growth and Resistance Against Streptococcus agalactiae by Enrichment of Nile Tilapia (Oreochromis niloticus) Diet with Leucas aspera. Fish Shellfish Immunol (2020) 97:165-72. doi: 10.1016/ j.fsi.2019.12.043

79. Mirghaed AT, Hoseini SM, Hoseinifar SH, Van Doan H. Effects of Dietary Thyme (Zataria multiflora) Extract on Antioxidant and Immunological Responses and Immune-Related Gene Expression of Rainbow Trout (Oncorhynchus mykiss) juveniles. Fish Shellfish Immunol (2020) 106:502-9. doi: 10.1016/j.fsi.2020.08.002

80. Tasa H, Imani A, Moghanlou KS, Nazdar N, Moradi-Ozarlou M. Aflatoxicosis in Fingerling Common Carp (Cyprinus carpio) and Protective Effect of Rosemary and Thyme Powder: Growth Performance and Digestive Status. Aquaculture (2020) 527:1-7. doi: 10.1016/ j.aquaculture.2020.735437

81. Zoral MA, Ishikawa Y, Ohshima T, Futami K, Endo M, Maita M, et al. Toxicological Effects and Pharmacokinetics of Rosemary (Rosmarinus officinalis) Extract in Common Carp (Cyprinus carpio). Aquaculture (2018) 495:955-60. doi: 10.1016/j.aquaculture.2018.06.048

82. Hernandez A, Garcia Garcia B, Caballero MJ, Hernandez MD. Preliminary inSights into the Incorporation of Rosemary Extract (Rosmarinus officinalis L.) in Fish Feed: Influence on Performance and Physiology of Gilthead Seabream (Sparus aurata). Fish Physiol Biochem (2015) 41(4):1065-74. doi: 10.1007/s10695-015-0069-2

83. Vazirzadeh A, Jalali S, Farhadi A. Antibacterial Activity of Oliveria decumbens Against Streptococcus iniae in Nile Tilapia (Oreochromis niloticus) and its Effects on Serum and Mucosal Immunity and Antioxidant Status. Fish Shellish Immunol (2019) 94:407-16. doi: $10.1016 /$ j.fsi.2019.09.025

84. Abdel-Tawwab M, Adeshina I, Jenyo-Oni A, Ajani EK, Emikped BO. Growth, Physiological, Antioxidants, and Immune Response of African Catfish, Clarias gariepinus (B.), to Dietary Clove Basil, Ocimum gratissimum, leaf extract and its susceptibility to Listeria Monocytogenes infection. Fish Shellfish Immunol (2018) 78:346-54. doi: 10.1016/j.fsi.2018.04.057
85. Brum A, Cardoso L, Chagas EC, Maia Chaves FC, Pedreira Mourino JL, Martins ML. Histological Changes in Nile Tilapia Fed Essential Oils of Clove Basil and Ginger After Challenge With Streptococcus agalactiae. Aquaculture (2018) 490:98-107. doi: 10.1016/j.aquaculture.2018.02.040

86. Sutili FJ, Velasquez A, Pinheiro CG, Heinzmann BM, Gatlin DMIII, Baldisserotto B. Evaluation of Ocimum americanum Essential Oil as an Additive in Red Drum (Sciaenops ocellatus) Diets. Fish Shellfish Immunol (2016) 56:155-61. doi: 10.1016/j.fsi.2016.07.008

87. Mousavi E, Mohammadiazarm H, Mousavi SM, Ghatrami ER. Effects of inUlin, Savory and Onion Powders in Diet of Juveniles Carp Cyprinus carpio (linnaeus 1758) on Gut Micro Flora, Immune Response And Blood Biochemical Parameters. Turkish J Fisheries Aquat Sci (2016) 16(4):831-8. doi: 10.4194/1303-2712-v16_4_09

88. Motlag HA, Safari O, Selahvarzi Y, Baghalian A, Kia E. Non-Specific Immunity Promotion in Response to Garlic Extract Supplemented Diets in Female Guppy (Poecilia reticulata). Fish Shellfish Immunol (2020) 97:969. doi: 10.1016/j.fsi.2019.12.007

89. Khan MS, Qureshi NA, Jabeen F, Wajid M, Sabri S, Shakir M. The Role of Garlic Oil in the Amelioration of Oxidative Stress and Tissue Damage in Rohu Labeo rohita Treated With Silver Nanoparticles. Fisheries Science (2020) 86(2):255-69. doi: 10.1007/s12562-020-01403-7

90. Foysal MJ, Alam M, Momtaz F, Chaklader MR, Siddik MAB, Cole A, et al. Dietary Supplementation of Garlic (Allium sativum) Modulates Gut Microbiota and Health Status of Tilapia (Oreochromis niloticus) Against Streptococcus iniae Infection. Aquaculture Res (2019) 50(8):2107-16. doi: 10.1111/are.14088

91. Kim JH, Fridman S, Borochov-Neori H, Sinai T, Zilberg D. Evaluating the Use of Garlic (Allium sativum) for the Remedy of Cryptocaryon irritans in Guppies (Poecilia reticulata). Aquaculture Res (2019) 50(2):431-8. doi: 10.1111/are.13904

92. Büyükdeveci ME, Balcázar JL, Demirkale İ., Dikel S. Effects of GarlicSupplemented Diet on Growth Performance and Intestinal Microbiota of Rainbow Trout (Oncorhynchus mykiss). Aquaculture (2018) 486:170-4. doi: $10.1016 /$ j.aquaculture.2017.12.022

93. Ghehdarijani MS, Hajimoradloo A, Ghorbani R, Roohi Z. The Effects of Garlic-Supplemented Diets on Skin Mucosal Immune Responses, Stress Resistance and Growth Performance of the Caspian Roach (Rutilus rutilus) fry. Fish Shellfish Immunol (2016) 49:79-83. doi: 10.1016/j.fsi.2015.12.021

94. Nicula M, Dumitrescu G, Pacala N, Tulcan C, Dragomirescu M, Stef L, et al. Garlic, Cilantro and Chlorella's Effect on Gill Histoarchitecture Changes in cd-Intoxicated Prussian Carp (Carassius gibelio). Romanian Biotechnol Letters (2016) 21(5):11932-40. doi: 10.25083/rbl

95. Bello OS, Emikpe BO, Olaifa FE. The body weight changes and gut morphometry of Clarias gariepinus juveniles on feeds supplemented with walnut (Tetracarpidium conophorum) leaf and onion (Allium cepa) bulb residues. Int J Morphology (2012) 30(1):253-7. doi: 10.4067/s071795022012000100045

96. Zhao L, Yuan B-D, Zhao J-L, Jiang N, Zhang A-Z, Wang G-Q, et al. Amelioration of Hexavalent Chromium-Induced Bioaccumulation, Oxidative Stress, Tight Junction Proteins and Immune-Related Signaling Factors by Allium mongolicum regel Flavonoids in Ctenopharyngodon idella. Fish Shellfish Immunol (2020) 106:993-1003. doi: 10.1016/j.fsi.2020.09.005

97. Kong Y-D, Li M, Xia C-G, Zhao J, Niu X-t, Shan X-F, et al. The Optimum Thymol Requirement in Diets of Channa argus: Effects on Growth, Antioxidant Capability, Immune Response and Disease Resistance. Aquaculture Nutr (2021) 00:1-11. doi: 10.1111/anu.13217

98. Morselli MB, Baldissera MD, Souza CF, Reis JH, Baldisserotto B, Sousa AA, et al. Effects of Thymol Supplementation on Performance, Mortality and Branchial Energetic Metabolism in Grass Carp Experimentally Infected by Aeromonas hydrophila. Microbial Pathogenesis (2020) 139:103915. doi: 10.1016/j.micpath.2019.103915

99. El-Naby ASA, Al-Sagheer AA, Negm SS, Naiel MAE. Dietary Combination of Chitosan Nanoparticle and Thymol Affects Feed Utilization, Digestive Enzymes, Antioxidant Status, and Intestinal Morphology of Oreochromis niloticus. Aquaculture (2020) 515:734577. doi: 10.1016/j.aquaculture. 2019.734577

100. Giannenas I, Triantafillou E, Stavrakakis S, Margaroni M, Mavridis S, Steiner $\mathrm{T}$, et al. Assessment of Dietary Supplementation With Carvacrol or Thymol 
Containing Feed Additives on Performance, Intestinal Microbiota and Antioxidant Status of Rainbow Trout (Oncorhynchus mykiss). Aquaculture (2012) 350:26-32. doi: 10.1016/j.aquaculture.2012.04.027

101. Jia R, Du J, Cao L, Feng W, Xu P, Yin G. Effects of Dietary Baicalin Supplementation on Growth Performance, Antioxidative Status and Protection Against Oxidative Stress-Induced Liver Injury in Gift Tilapia (Oreochromis niloticus). Comp Biochem Physiol C-Toxicology Pharmacol (2021) 240:1-10. doi: 10.1016/j.cbpc.2020.108914

102. Huang W, Yao C, Liu Y, Xu N, Yin Z, Xu W, et al. Dietary Allicin Improved the Survival and Growth of Large Yellow Croaker (Larimichthys crocea) Larvae via Promoting Intestinal Development, Alleviating Inflammation and Enhancing Appetite. Front Physiol (2020) 11:587674. doi: 10.3389/ fphys.2020.587674

103. Ning L, Zhang X, Zhang D, Hu Y, Li Y. The Benefits of Blend Essential Oil for Gift Tilapia on the Digestion, Antioxidant, and Muscle Quality During Cold Storage. Aquaculture (2021) 533:1-9. doi: 10.1016/j.aquaculture. 2020.736097

104. Serradell A, Torrecillas S, Makol A, Valdenegro V, Fernández-Montero A, Acosta F, et al. Prebiotics and Phytogenics Functional Additives in Low Fish Meal and Fish Oil Based Diets for European Sea Bass (Dicentrarchus labrax): Effects on Stress and Immune Responses. Fish Shellfish Immunol (2020) 100:219-29. doi: 10.1016/j.fsi.2020.03.016

105. Rimoldi S, Torrecillas S, Montero D, Gini E, Makol A, Valdenegro VV, et al. Assessment of Dietary Supplementation with Galactomannan Oligosaccharides and Phytogenics on Gut Microbiota of European Sea Bass (Dicentrarchus labrax) Fed Low Fishmeal and Fish Oil Based Diet. PloS One (2020) 15(4):1-30. doi: 10.1371/journal.pone.0231494

106. Reyes-Cerpa S, Vallejos-Vidal E, Jose Gonzalez-Brown M, Morales-Reyes J, Perez-Stuardo D, Vargas D, et al. Effect of Yeast (Xanthophyllomyces dendrorhous) and Plant (Saint John's Wort, Lemon Balm, and Rosemary) Extract Based Functional Diets on Antioxidant and Immune Status of Atlantic Salmon (Salmo salar) Subjected to Crowding Stress. Fish Shellish Immunol (2018) 74:250-9. doi: 10.1016/j.fsi.2017.12.061

107. Ran C, Hu J, Liu WS, Liu Z, He SX, Dan BCT, et al. Thymol and Carvacrol Affect Hybrid Tilapia Through the Combination of Direct Stimulation and an Intestinal Microbiota-Mediated Effect: Insights From a Germ-Free Zebrafish Model. J Nutr (2016) 146(5):1132-40. doi: 10.3945/jn.115.229377

108. Perez-Sanchez J, Benedito-Palos L, Estensoro I, Petropoulos Y, CalduchGiner JA, Browdy CL, et al. Effects of Dietary Next Enhance 150 on Growth Performance and Expression of Immune and Intestinal Integrity Related Genes in Gilthead Sea Bream (Sparus aurata L.). Fish Shellfish Immunol (2015) 44(1):117-28. doi: 10.1016/j.fsi.2015.01.039

109. Lombrea A, Antal D, Ardelean F, Avram S, Pavel IZ, Vlaia L, et al. A recent insight regarding the phytochemistry and bioactivity of Origanum vulgare $\mathrm{L}$. essential oil. Int J Mol Sci (2020) 21(24):9653. doi: 10.3390/ijms21249653

110. Hosseinzadeh S, Jafarikukhdan A, Hosseini A, Armand R. The Application of Medicinal Plants in Traditional and Modern Medicine: A Review of Thymus vulgaris. Int J Clin Med (2015) 6(9):8. doi: 10.4236/ijcm.2015.69084

111. Kachur K, Suntres Z. The Antibacterial Properties of Phenolic isomers, Carvacrol and Thymol. Crit Rev Food Sci Nutr (2020) 60(18):3042-53. doi: 10.1080/10408398.2019.1675585

112. Araruna ME, Serafim C, Alves Júnior E, Hiruma-Lima C, Diniz M, Batista L. Intestinal Anti-Inflammatory Activity of Terpenes in Experimental Models (2010-2020): A Review. Molecules (2020) 25(22):5430. doi: 10.3390/ molecules 25225430

113. Llana-Ruiz-Cabello M, Gutiérrez-Praena D, Puerto M, Pichardo S, Jos Á., Cameán AM. In Vitro Pro-Oxidant/Antioxidant Role of Carvacrol, Thymol and Their Mixture in the Intestinal Caco-2 Cell Line. Toxicol Vitro (2015) 29 (4):647-56. doi: 10.1016/j.tiv.2015.02.006

114. Somensi N, Rabelo TK, Guimarães AG, Quintans-Junior LJ, de Souza Araújo AA, Moreira JCF, et al. Carvacrol Suppresses LPS-Induced ProInflammatory Activation in Raw 264.7 Macrophages Through Erk1/2 and Nf-kB Pathway. Int Immunopharmacol (2019) 75:105743. doi: 10.1016/ j.intimp.2019.105743

115. Zhou E, Fu Y, Wei Z, Yu Y, Zhang X, Yang Z. Thymol Attenuates Allergic Airway Inflammation in Ovalbumin (ova)-Induced Mouse Asthma. Fitoterapia (2014) 96:131-7. doi: 10.1016/j.fitote.2014.04.016
116. Wu H, Jiang K, Yin N, Ma X, Zhao G, Qiu C, et al. Thymol Mitigates Lipopolysaccharide-Induced Endometritis by Regulating the tlr4- and RosMediated Nf-אB Signaling Pathways. Oncotarget (2017) 8(12):20042-55. doi: 10.18632 /oncotarget.15373

117. Liu SD, Song MH, Yun W, Lee JH, Kim HB, Cho JH. Effect of Carvacrol Essential Oils on Immune Response and Inflammation-Related Genes Expression in Broilers Challenged by Lipopolysaccharide. Poultry Science (2019) 98(5):2026-33. doi: 10.3382/ps/pey575

118. Xu H, Delling M, Jun JC, Clapham DE. Oregano, Thyme and Clove-Derived Flavors and Skin Sensitizers Activate Specific trp Channels. Nat Neurosci (2006) 9(5):628-35. doi: 10.1038/nn1692

119. Lee SP, Buber MT, Yang Q, Cerne R, Cortés RY, Sprous DG, et al. Thymol and Related Alkyl Phenols Activate the htrpal Channel. Br J Pharmacol (2008) 153(8):1739-49. doi: 10.1038/bjp.2008.85

120. Khalil M, Alliger K, Weidinger C, Yerinde C, Wirtz S, Becker C, et al. Functional Role of Transient Receptor Potential Channels in immune cells and epithelia. Front Immunol (2018) 9:1-7. doi: 10.3389/fimmu.2018.00174

121. Clement D, Goodridge JP, Grimm C, Patel S, Malmberg K-J. Trp Channels as Interior Designers: Remodeling the Endolysosomal Compartment in Natural Killer Cells. Front Immunol (2020) 11:1-15. doi: 10.3389/fimmu.2020.00753

122. Feske S, Wulff $\mathrm{H}$, Skolnik EY. Ion Channels in Innate and Adaptive Immunity. Annu Rev Immunol (2015) 33(1):291-353. doi: 10.1146/ annurev-immunol-032414-112212

123. Ueda T, Yamada T, Ugawa S, Ishida Y, Shimada S. Trpv3, a Thermosensitive Channel is Expressed in Mouse Distal Colon Epithelium. Biochem Biophys Res Commun (2009) 383(1):130-4. doi: 10.1016/j.bbrc.2009.03.143

124. Galindo-Villegas J, Montalban-Arques A, Liarte S, de Oliveira S, PardoPastor C, Rubio-Moscardo F, et al. Trpv4-Mediated Detection of Hyposmotic Stress By Skin Keratinocytes Activates Developmental Immunity. J Immunol (2016) 196(2):738-49. doi: 10.4049/jimmunol. 1501729

125. Alagawany M, Farag MR, Abdelnour SA, Elnesr SS. A reView on the Beneficial Effect of Thymol on Health and Production of Fish. Rev Aquaculture (2021) 13(1):632-41. doi: 10.1111/raq.12490

126. Satyal P, Craft JD, Dosoky NS, Setzer WN. The Chemical Compositions of the Volatile Oils of Garlic (Allium sativum) and Wild Garlic (Allium vineale). Foods (2017) 6(8):63. doi: 10.3390/foods6080063

127. Borlinghaus J, Albrecht F, Gruhlke MCH, Nwachukwu ID, Slusarenko AJ. Allicin: Chemistry and Biological Properties. Molecules (2014) 19(8):12591618. doi: 10.3390/molecules190812591

128. Lawson LD, Hunsaker SM. Allicin Bioavailability and Bioequivalence From Garlic Supplements and Garlic Foods. Nutrients (2018) 10(7):812. doi: $10.3390 /$ nu10070812

129. Rose P, Moore PK, Whiteman M, Zhu Y-Z. An Appraisal of Developments in Allium Sulfur Chemistry: Expanding the Pharmacopeia of Garlic. Molecules (2019) 24(21):4006. doi: 10.3390/molecules24214006

130. Anthony JP, Fyfe L, Smith H. Plant Active Components - A Resource for Antiparasitic Agents? Trends Parasitology (2005) 21(10):462-8. doi: 10.1016/ j.pt.2005.08.004

131. Takizawa F, Koppang EO, Ohtani M, Nakanishi T, Hashimoto K, Fischer U, et al. Constitutive High Expression of Interleukin-4/13a and Gata-3 in Gill and Skin of Salmonid Fishes Suggests That These Tissues Form th2-Skewed Immune Environments. Mol Immunol (2011) 48(12):1360-8. doi: 10.1016/ j.molimm.2011.02.014

132. Marchese A, Barbieri R, Sanches-Silva A, Daglia M, Nabavi SF, Jafari NJ, et al. Antifungal and Antibacterial Activities of Allicin: A Review. Trends Food Sci Technology (2016) 52:49-56. doi: 10.1016/j.tifs.2016.03.010

133. Lu X, Rasco BA, Jabal JMF, Aston DE, Lin M, Konkel ME. Investigating Antibacterial Effects of Garlic (Allium sativum) Concentrate and GarlicDerived Organosulfur Compounds on Campylobacter Jejuni by Using Fourier Transform Infrared Spectroscopy, Raman Spectroscopy, and Electron Microscopy. Appl Environ Microbiol (2011) 77(15):5257-69. doi: 10.1128/AEM.02845-10

134. Berginc K, Milisav I, Kristl A. Garlic Flavonoids and Organosulfur Compounds: Impact on the Hepatic Pharmacokinetics of Saquinavir and Darunavir. Drug Metab Pharmacokinetics (2010) 25(6):521-30. doi: 10.2133/dmpk.dmpk-10-rg-053 
135. Effner R, Hiller J, Eyerich S, Traidl-Hoffmann C, Brockow K, Triggiani M, et al. Cytochrome p450s in Human Immune Cells Regulate il-22 and c-kit via an ahr Feedback Loop. Sci Rep (2017) 7(1):44005. doi: 10.1038/ srep 44005

136. Feng C, Luo Y, Nian Y, Liu D, Yin X, Wu J, et al. Diallyl Disulfide Suppresses the Inflammation and Apoptosis Resistance Induced by dca Through Ros and the Nf- $\mathrm{\kappa B}$ Signaling Pathway in Human Barrett's Epithelial Cells. Inflammation (2017) 40(3):818-31. doi: 10.1007/s10753-017-0526-4

137. Zhang Y, Wang Y, Zhang F, Wang K, Liu G, Yang M, et al. Allyl Methyl Disulfide Inhibits il-8 and ip-10 Secretion in Intestinal Epithelial Cells via the Nf-кB Signaling Pathway. Int Immunopharmacology (2015) 27(1):156-63. doi: 10.1016/j.intimp.2015.05.013

138. Fasolino I, Izzo AA, Clavel T, Romano B, Haller D, Borrelli F. Orally Administered Allyl Sulfides From Garlic Ameliorate Murine Colitis. Mol Nutr Food Res (2015) 59(3):434-42. doi: 10.1002/mnfr.201400347

139. Wallace JL, Motta J-P, Buret AG. Hydrogen Sulfide: An Agent of Stability at The Microbiome-Mucosa Interface. Am J Physiology-Gastrointestinal Liver Physiol (2018) 314(2):G143-9. doi: 10.1152/ajpgi.00249.2017

140. Bae CH, Kwak DS, Ye SB, Song S-Y, Kim Y-D. Diallyl Disulfide Induces muc5b Expression via erk2 in Human Airway Epithelial Cells. Phytotherapy Res (2012) 26(2):197-203. doi: 10.1002/ptr.3531

141. Lee Y, Lee S-h, Gadde UD, Oh S-t, Lee S-j, Lillehoj HS. Dietary Allium Hookeri Reduces Inflammatory Response and Increases Expression of Intestinal Tight Junction Proteins in LPS-Induced Young Broiler Chicken. Res Veterinary Science (2017) 112:149-55. doi: 10.1016/j.rvsc.2017.03.019

142. Arreola R, Quintero-Fabián S, López-Roa RI, Flores-Gutiérrez EO, ReyesGrajeda JP, Carrera-Quintanar L, et al. Immunomodulation and AntiInflammatory Effects of Garlic Compounds. J Immunol Res (2015) 2015:401630-0. doi: 10.1155/2015/401630

143. Schepetkin IA, Kirpotina LN, Khlebnikov AI, Balasubramanian N, Quinn MT. Neutrophil Immunomodulatory Activity of Natural Organosulfur Compounds. Molecules (2019) 24(9):1809. doi: 10.3390/molecules24091809

144. Macpherson LJ, Geierstanger BH, Viswanath V, Bandell M, Eid SR, Hwang S, et al. The Pungency of Garlic: Activation of trpal and trpv1 in Response to Allicin. Curr Biol (2005) 15(10):929-34. doi: 10.1016/j.cub.2005.04.018

145. Koizumi K, Iwasaki Y, Narukawa M, Iitsuka Y, Fukao T, Seki T, et al. Diallyl Sulfides in Garlic Activate Both trpal and trpvl. Biochem Biophys Res Commun (2009) 382(3):545-8. doi: 10.1016/j.bbrc.2009.03.066

146. Yassaka RT, Inagaki H, Fujino T, Nakatani K, Kubo T. Enhanced Activation of the Transient Receptor Potential Channel trpal by Ajoene, an Allicin Derivative. Neurosci Res (2010) 66(1):99-105. doi: 10.1016/j.neures. 2009.09.1712

147. Sato S, Sekine Y, Kakumu Y, Hiramoto T. Measurement of Diallyl Disulfide and Allyl Methyl Sulfide Emanating From Human Skin Surface AND Influence of Ingestion of Grilled Garlic. Sci Rep (2020) 10(1):465. doi: 10.1038/s41598-019-57258-1

148. Lulijwa R, Rupia EJ, Alfaro AC. Antibiotic use in Aquaculture, Policies and Regulation, Health and Environmental Risks: A Review of the Top 15 Major Producers. Rev Aquaculture (2020) 12(2):640-63. doi: 10.1111/raq.12344

149. Schar D, Klein EY, Laxminarayan R, Gilbert M, Van Boeckel TP. Global Trends in Antimicrobial Use in Aquaculture. Sci Rep (2020) 10(1):21878. doi: 10.1038/s41598-020-78849-3
150. More SJ. European Perspectives on Efforts to Reduce Antimicrobial Usage in Food Animal Production. Irish Veterinary J (2020) 73(1):2. doi: 10.1186/ s13620-019-0154-4

151. Markets and Markets. Phytogenics Feed Additives Market by Type (Essential Oils, Flavonoids, Saponins, and Oleoresins), Livestock (Poultry, Swine, Ruminants, and Aquatic Animals), Source (Herbs \& Spices, Flowers, and Fruits \& Vegetables), Region - Global Forecast to 2025, Markets \& Markets Vol. 264. (2020). p. 5135729.

152. Vallejos-Vidal E, Reyes-López F, Teles M, MacKenzie S. The Response of Fish to Immunostimulant Diets. Fish Shellfish Immunol (2016) 56:34-69. doi: $10.1016 /$ j.fsi.2016.06.028

153. Galindo-Villegas J, Hosokawa H. Immunostimulants: Towards Temporary Prevention of diseAses in Marine Fish. In: D R.M, LE Cruz Suarez, MG Nieto López, D Villarreal, U Scholz and M González, editors. Avances en Nutrición Acuicola VII. Monterrey, México: Universidad Autónoma de Nuevo León (2004). p. 279-319.

154. Galindo-Villegas J, Fukada H, Masumoto T, Hosokawa H. Effect of Dietary Immunostimulants on Some Innate Immune Responses and Disease Resistance Against Edwardsiella tarda Infection in Japanese Flounder (Paralichthys olivaceus). Aquaculture Science (2006) 54(2):153-62. doi: 10.11233/aquaculturesci1953.54.153

155. Galindo-Villegas J, Masumoto T, Hosokawa H. Effect of Continuous and Interval Administration of Peptidoglycan on Innate Immune Response and Disease Resistance in Japanese Flounder Paralichthys olivaceus. Aquaculture Science (2006) 54(2):163-70. doi: 10.11233/aquaculturesci1953.54.163

156. Yap PSX, Yiap BC, Ping HC, Lim SHE. Essential Oils, a New Horizon in Combating Bacterial Antibiotic Resistance. Open Microbiol J (2014) 8:6-14. doi: $10.2174 / 1874285801408010006$

157. Willing BP, Pepin DM, Marcolla CS, Forgie AJ, Diether NE, Bourrie BCT. Bacterial Resistance to Antibiotic Alternatives: A Wolf in Sheep's Clothing? Anim Frontiers (2018) 8(2):39-47. doi: 10.1093/af/vfy003

158. Dezfooli SM, Gutierrez-Maddox N, Alfaro A, Seyfoddin A. Encapsulation for delivering bioactives in aquaculture. Rev Aquaculture (2019) 11(3):631-60. doi: $10.1111 /$ raq. 12250

159. Stevanović ZD, Bošnjak-Neumüller J, Pajić-Lijaković I, Raj J, Vasiljević M. Essential Oils as Feed Additives-Future Perspectives. Molecules (2018) 23 (7):1717. doi: 10.3390/molecules23071717

Conflict of Interest: JF is employed by TECNOVIT-FARMFAES S.L. FER-L is a senior research associate of the Consorcio Tecnológico de Sanidad Acuicola, Ictio Biotechnologies S.A. (Chile).

The remaining authors declare that the research was conducted in the absence of any commercial or financial relationships that could be construed as a potential conflict of interest.

Copyright (๑) 2021 Firmino, Galindo-Villegas, Reyes-López and Gisbert. This is an open-access article distributed under the terms of the Creative Commons Attribution License (CC BY). The use, distribution or reproduction in other forums is permitted, provided the original author(s) and the copyright owner(s) are credited and that the original publication in this journal is cited, in accordance with accepted academic practice. No use, distribution or reproduction is permitted which does not comply with these terms. 